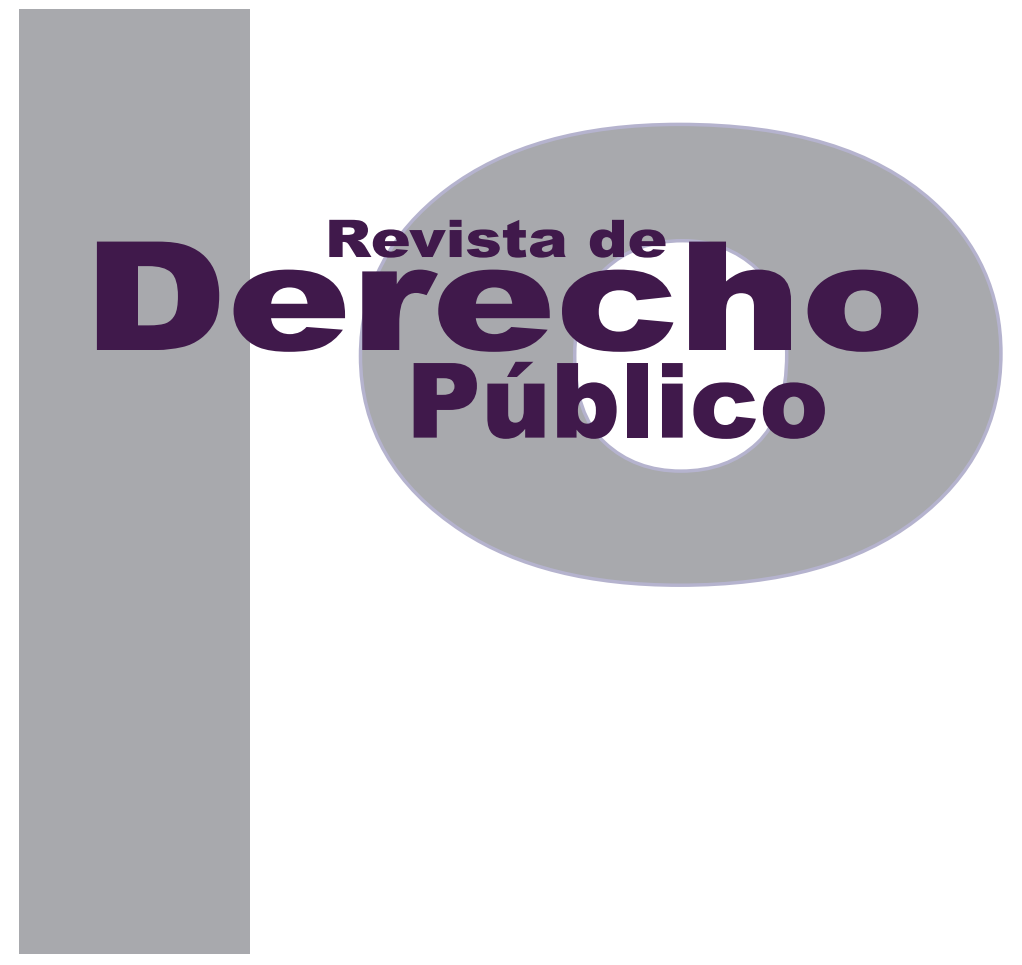

\title{
ACCESO DE LAS PERSONAS CON DISCAPACIDAD A LOS SERVICIOS PÚBLICOS: DERECHO IMPOSTERGABLE CON BASE EN EL CONTROL DIFUSO DE CONVENCIONALIDAD
}

\author{
Miguel Ángel Abdiel Barboza lópez
}

Artículo de reflexión

Universidad de los Andes

Facultad de Derecho

Revista de Derecho Público N. ${ }^{\circ} 32$

Enero - Junio de 2014. ISSN 1909-7778 


\title{
Acceso de las personas con discapacidad a los servicios públicos: derecho impostergable con base en el control difuso de convencionalidad
}

\section{Resumen}

Este artículo analiza la problemática que afrontan actualmente las personas con discapacidad en el acceso a los servicios públicos. Se enfoca en analizar la débil comprensión del término discapacidad, las barreras socionormativas a las que se enfrentan, los efectos de no reconocer los compromisos asumidos por los Estados al ratificar la Convención Americana de Derechos Humanos y los principales instrumentos regionales e internacionales que regulan los derechos de estas personas. En razón a ello, los Estados se plantean grandes retos en cuanto a asumir el control difuso de convencionalidad, desarrollando dos de sus variantes para amparar los derechos de las personas con discapacidad: social y jurídica. Reto que hoy tiene que asumirse desde la situación especial de "alta vulnerabilidad" a la que está sujeta esta población en el desarrollo de sus actividades, teniendo en cuenta los obstáculos del entorno social en cuanto a su accesibilidad a los servicios públicos.

Palabras clave: Discapacidad, acceso, servicios públicos, barreras físicas, discriminación, control de convencionalidad, vulnerabilidad, convención.

\section{Access for persons with disabilities to public services: urgent right based on the conventional fuzzy control of compliance}

\begin{abstract}
This article analyzes the current problems faced by persons with disabilities in access to public services, focusing on analyzing the weak understanding of the term disability, and socio- normative barriers they face, tackling the effects of not recognizing generated assumed the duties following the ratification of the American Convention on Human Rights as well as major regional and international instruments governing the rights of persons with disabilities. Because major challenges presented to it by the States to assume the Fuzzy Control Conventionality, developing two variants to protect the rights of persons with disabilities: social and legal. Challenge today is to be assumed from the special situation of "high vulnerability" that are subject persons with disabilities in the development of its activities in the social environment that is manifested in the accessibility of public services.
\end{abstract}

Keywords: Disability, access, utilities, physical barriers, discrimination, control of compliance, vulnerability convention.

\section{Acesso das pessoas com deficiência aos serviços públicos: direito impostergável com base no controle difuso de convencionalidade}

\section{Resumo}

Este artigo analisa a problemática que as pessoas com deficiência enfrentam atualmente, o acesso aos serviços públicos. Enfoca-se em analisar a fraca compreensão do término deficiência, as barreiras socionormativas às que se enfrentam, os efeitos de não reconhecer os compromissos assumidos pelos Estados ao ratificar a Convenção Americana de Direitos Humanos e os principais instrumentos regionais e internacionais que regulam os direitos destas pessoas. Em razão disso, os Estados propõem grandes desafios em assumir o controle difuso de convencionalidade, desenvolvendo duas de suas variantes para amparar os direitos das pessoas com deficiência: social e jurídica. Desafio que hoje tem que ser assumido desde a situação especial de "alta vulnerabilidade" à que está sujeita esta população no desenvolvimento de suas atividades, considerando os obstáculos do entorno social quanto a sua acessibilidade aos serviços públicos.

Palavras-chave: Deficiência, acesso, serviços públicos, barreiras físicas, discriminação, controle de convencionalidade, vulnerabilidade, convenção. 


\section{SUMARIO}

Introducción - I. EL INCOMPRENDIDO TÉRMINO “DISCAPACIDAD”, IMPEDIMENTO PARA EL ACCESO A LOS SERVICIOS PÚBLICOS - II. CONFLICTOS SOCIONORMATIVOS DEL RESPETO DEL DERECHO DE LAS PERSONAS CON DISCAPACIDAD AL ACCESO A LOS SERVICIOS PÚBLICOS - A. El doble contenido del control de convencionalidad - B. La "no discriminación" derecho titular de las personas con discapacidad y su regulación normativa en el derecho internacional de los derechos humanos - 1. Necesidad de un trato no discriminatorio en el acceso a los servicios públicos - 2. "No discriminación" y su necesaria interrelación con el acceso a la personalidad jurídica, igualdad ante la ley y vida privada - 3. "Vida", derecho impostergable de las personas con discapacidad - III. CONTROL DE CONVENCIONALIDAD Y EL DERECHO AL ACCESO A LOS SERVICIOS PÚBLICOS - IV. CONCLUSIONES - Bibliografía. 


\title{
Acceso de las personas con discapacidad a los servicios públicos: derecho impostergable con base en el control difuso de convencionalidad ${ }^{1}$
}

\author{
Miguel Ángel Abdiel Barboza López²
}

En los casos de personas con discapacidad congénita, como me sucede a mí, la familia espera con frecuencia poco de ellos, de manera que, en primer lugar, las expectativas son escasas, en segundo lugar, los obstáculos físicos que existen en la comunidad pueden impedirles el acceso a su comunidad, y en tercer lugar, las barreras sociales pueden impedirles también el acceso a su comunidad

Linda Mastandrea

Paraolímpica y abogada especializada en discapacidad (Chicago, EE. UU.)

Introducción

Para nadie es desconocido que las personas con discapacidad, fuera de conformar uno de los grupos más marginados del mundo, presentan los peores resultados en aspectos sanitarios y académicos, entre otros. ${ }^{3}$ El panorama es

1 Cómo citar este artículo: Barboza López, M. A. (Junio, 2014). Acceso de las personas con discapacidad a los servicios públicos: derecho impostergable con base en el control difuso de convencionalidad. Revista de Derecho Público, 32.

2 Abogado, Universidad Católica de Santa María del Perú. Especialización en Derecho Internacional Humanitario y Derechos Humanos, Universidad de San Martín de Porres (Perú) y en Gobernabilidad y Gerencia Política, Pontifica Universidad Católica del Perú. Beca de estudios en Género por la OEA y la ESAP, y en Gestión en Políticas Públicas por el BID. Mención especial "Líder Emergente" en los premios Victory Awards (Nueva York). Juez y participante en eventos internacionales en temas de derechos humanos en Perú, Bolivia y Washington D. C. Director de Asuntos en Español de Foreign Affairs Institute (Colombia, Estados Unidos, Perú y Venezuela). Autor de artículos en materia de género e integración andina. Correo: miguel.barboza@foreignaffairsinstitute.com

3 Naciones Unidas y Organización Mundial de la Salud. (Septiembre 2013). 10 datos sobre la discapacidad. Recuperado de: www.who.int/ features/factfiles/disability/es/. alarmante si se tiene en cuenta que mil millones de personas, es decir, la séptima parte de la población mundial, sobrelleva algún grado de discapacidad. ${ }^{4}$

Una de las barreras que enfrentan a diario estas personas es la falta de acceso a los servicios públicos, especialmente el transporte, la información y la comunicación. Eliminarlas es hacer posible su participación en la educación, el empleo y la vida social; reducir su aislamiento y dependencia; y contrarrestar el incumplimiento de las normas que contribuyen a garantizarles los derechos en este sentido. Lograrlo exige la cooperación entre el sector público y el privado, así como de las organizaciones y empresas dedicadas al planeamiento, diseño y ejecución de proyectos

4 Un nuevo informe muestra que más de 1000 millones de personas con discapacidad deben superar a diario obstáculos importantes. Naciones Unidas, Organización Mundial de la Salud y Banco Mundial. (9 de junio, 2011). Comunicado de Prensa oms/13. New York: oms, p. 01. 
de infraestructura y servicios, y a la formación de personal en accesibilidad de acuerdo con parámetros universales, proceso que conlleva la concientización de planificadores, arquitectos, ingenieros, diseñadores y de la sociedad en general desde la educación pública y privada. ${ }^{5}$

Tales aspectos actualmente son incumplidos total o parcialmente, vulnerando toda una gama de derechos - a la vida en comunidad, a la vida privada, a la igualdad, a la personalidad jurídica, entre otros- que están amparados en la dignidad de la persona humana y en instrumentos como la Convención Americana de Derechos Humanos (en adelante CADH), la Convención Interamericana para la Eliminación de todas las formas de Discriminación contra las Personas con Discapacidad, la Convención Internacional sobre Ios Derechos de las Personas con Discapacidad, entre otros que deben guiar el actuar estatal.

Uno de los problemas que agrava la no garantía en el acceso a los servicios públicos de las personas con discapacidad por parte del Estado es la errada comprensión del término discapacidad y de los elementos que de él emergen. Como resultado, se produce el incumplimiento de los parámetros convencionales y del control de convencionalidad, como mecanismo para verificar que una ley, reglamento $o$ acto de las autoridades estatales se ajusten a las normas, principios y obligaciones de la CADH, principalmente.

$5 \quad$ Naciones Unidas, Organización Mundial de la Salud y Banco Mundial. (9 de junio de 2011). Informe mensual sobre la discapacidad (WHO/ NMH/VIP/11.03). New York: oms, BID, p. 16.
Este estudio se basará en el control de convencionalidad difuso, referido primero a lo social, para desde esta abordar el marco jurídico en su regulación, ejecución y supervisión.

\section{EL INCOMPRENDIDO TÉRMINO “DISCAPACIDAD", IMPEDIMENTO PARA EL ACCESO A LOS SERVICIOS PÚBLICOS}

Hablar de discapacidad implica precisar el significado del término para evitar que en el contexto social se siga asociando con "incapacidad". Esta confusión lleva a los Estados y a los particulares a cometer un sin número de violaciones a los derechos humanos de las personas con discapacidad, y genera trabas políticas y sociales que impiden cumplir el corpus iuris de la $\mathrm{CADH}$.

En este orden, la Organización Mundial de la Salud (en adelante oms) aprobó en Murcia, en el año 2001, la nueva Clasificación Internacional del Funcionamiento, de la Discapacidad y de la Salud (CIF), conceptualizando la discapacidad como el término que engloba tanto las deficiencias, limitaciones en la actividad y restricciones en la participación, ${ }^{6}$ y entendiendo por deficiencias los problemas que afectan a una estructura o función corporal; por limitaciones de la actividad las dificultades para ejecutar acciones o tareas y por restricciones de la participación los problemas para participar en situaciones vitales. ${ }^{7}$

6 Egea García, C. y Saravia Sánchez, A. (Noviembre de 2001). Clasificaciones de la Organización Mundial de la Salud sobre discapacidad. Artículos y notas, p. 10.

7 lbíd., p. 10 
Tales componentes habían sido delineados por el Sistema Interamericano de Derechos Humanos con la aprobación de la Convención Interamericana para la Eliminación de todas las Formas de Discriminación contra las Personas con Discapacidad, el 07 de junio de 1999 en Ciudad de Guatemala, al definir discapacidad como: "deficiencia física, mental o sensorial, sea de naturaleza permanente o temporal, que limita la capacidad de ejercer una o más actividades esenciales de la vida diaria, que puede ser causada o agravada por el entorno económico-social". El amparo, si bien no está consignado textualmente en la $\mathrm{CADH}$, siempre ha estado implícito en el máximo principio que la rige: la defensa de la dignidad de la persona, y en tal virtud debe ser cumplido sin barreras de ninguna naturaleza, en el marco del control de convencionalidad.

Por su parte, la Organización de las Naciones Unidas (en adelante onU), el 13 de diciembre de 2006, en la ciudad de Nueva York, aprobó la Convención Internacional sobre los Derechos de las Personas con Discapacidad, instrumento internacional que plasma en su artículo primero: "las personas con discapacidad incluyen a aquellos que tengan deficiencias físicas, mentales, intelectuales o sensoriales a largo plazo que, al interactuar con diversas barreras, puedan impedir su participación plena y efectiva en la sociedad, en igualdad de condiciones con los demás". Concepto que de igual forma recoge los tres componentes de la definición desarrollada por la oms y la Convención para la Eliminación de todas las Formas de Discriminación contra las Personas con Discapacidad, enfatizando que "discapacidad" no solo implica tener una deficiencia física, mental o sensorial, sino el impacto negativo que esta pueda generar a la persona que la padece, en su desarrollo normal y adecuado en sociedad. Existe, pues, unidad en dichos instrumentos internacionales al definir la voz discapacidad.

\section{CONFLICTO SOCIONORMATIVO EN EL RESPETO DE LOS DERECHOS DE LAS PERSONAS CON DISCAPACIDAD AL ACCESO A LOS SERVICIOS PÚBLICOS}

\section{A. El doble contenido del control de convencionalidad}

Las limitaciones en la actividad y las restricciones en la participación, componentes encuadrados dentro del concepto de discapacidad, merecen ser amparados por los Estados en una doble obligación: en primer lugar, con el reconocimiento de los problemas que enfrentan las personas discapacitadas en la realidad social interna de cada país: control difuso de convencionalidad social; y, en segundo lugar, con la adecuación de la legislación interna a las normas adoptadas a nivel interamericano y que han sido ratificadas por los países: control difuso de convencionalidad jurídica, aspecto que será materia de análisis más adelante.

Acoplar ambos conceptos de control de convencionalidad realza la obligación de los Estados de analizar, conforme lo señala la Corte Interamericana de Derechos Humanos (en adelante CIDH), el modelo social para abordar la discapacidad, de modo que atienda no solo a la presencia de una 
deficiencia física, mental, intelectual o sensorial, sino a las barreras u obstáculos que socialmente impiden que estas personas puedan ejercer sus derechos de manera efectiva, ${ }^{8}$ entre otras ${ }^{9}$, barreras físicas o arquitectónicas ${ }^{10}$, comunicativas $^{11}$, actitudinales ${ }^{12}$ o socioeconómicas ${ }^{13}$.

\section{B. La "no discriminación", derecho} titular de las personas con discapacidad y su regulación normativa en el derecho internacional de los derechos humanos res vs. Argentina. Sentencia del 31 de agosto de 2012. (Excepciones Preliminares, Fondo, Reparaciones y Costas). Serie C n. ${ }^{\circ} 246$, párr. 133.

9 "El Comité insiste en que los obstáculos no son la discapacidad en sí misma, sino más bien una combinación de obstáculos sociales, culturales, de actitud y físicos que los niños con discapacidad encuentran en sus vidas diarias." Naciones Unidas, Comité de los Derechos del Niño. (27 de febrero de 2007). Observación General n. ${ }^{\circ}$ 9. Los derechos de los niños con discapacidad (CRC/C/GC/9), párr. 5.

10 "La inaccesibilidad física del transporte público y de otras instalaciones, en particular los edificios gubernamentales, las zonas comerciales, las instalaciones de recreo, entre otras, es un factor importante de marginación y exclusión de los niños con discapacidad y compromete claramente su acceso a los servicios, en particular la salud y la educación.” Ibíd., párr. 39.

11 "El acceso a la información y a los medios de comunicación, en particular las tecnologías y los sistemas de la información y de las comunicaciones, permite a los niños con discapacidad vivir en forma independiente y participar plenamente en todos los aspectos de la vida". Ibíd., párr. 37 .

12 "en lo que respecta a la discapacidad, también hay muchas circunstancias concretas que han influido en las condiciones de vida de las personas que la padecen: la ignorancia, el abandono, la superstición y el miedo son factores sociales que a lo largo de toda la historia han aislado a las personas con discapacidad y han retrasado su desarrollo." Naciones Unidas, Asamblea General. (4 de marzo de 1994). Normas uniformes sobre la igualdad de oportunidades para las personas con discapacidad. (AG/RES/48/96), párr. 3.

13 Corte Interamericana de Derechos Humanos. Caso Ximenes Lopez vs. Brasil. Sentencia de 4 de julio de 2006. (Fondo, Reparaciones y Costas). Serie C, n. ${ }^{\circ} 149$, párr. 104; Cfr., Convención Internacional sobre los Derechos de las Personas con Discapacidad, artículo III.2. y Naciones Unidas, Comité de Derechos Económicos, Sociales y Culturales. (12 de septiembre de 1994). Observación General $n .{ }^{\circ} 5$, Personas con discapacidad (E/C.12/1994/13), párr. 9.

\section{Necesidad de un trato no discriminatorio en el acceso a los servicios públicos}

La inaccesibilidad a los servicios públicos de las personas con discapacidad vulnera toda una gama de derechos, entre ellos el de no discriminación, que acorde con la clasificación del Instituto Interamericano de Derechos Humanos se enmarca en dos de sus subclasificaciones: el normalismo y la invisibilidad de las necesidades especiales.

El primero (normalismo) se enfoca desde la perspectiva de las personas que no tienen una discapacidad, presentando su experiencia como central y exclusiva de la vivencia humana, de ahí la falta de información visual o auditiva, la no eliminación de trampas u otros dispositivos que impiden el paso de la población con discapacidad; la segunda (invisibilidad de las necesidades especiales) se refiere a la imposibilidad de ver las necesidades de las personas con discapacidad, por ejemplo, la falta de rampas para el acceso arquitectónico o de información disponible en lenguajes distintos al escrito. ${ }^{14}$ Ambas clasificaciones detallan el problema de acceso a los servicios públicos, denunciando tanto la obligación de los particulares (privada) como del Estado (pública), decrecida por la falta de previsión normativa en el cumplimiento de dis-

14 Instituto Interamericano de Derechos Humanos. (Junio, 2008). Derechos de las personas con discapacidad, Módulo 6. San José de Costa Rica: IIDH, pp. 21-22. En dicho documento enuncia las distintas formas en que se manifiesta la discriminación hacia personas con discapacidad: “a) Normalismo, b) invisibilidad de las necesidades esenciales, c) el odio a las personas con discapacidad, d) sobregeneralización, e) sobreespecificidad, f) insensibilidad a la incapacidad, g) doble parámetro, h) deber de las personas con discapacidad, i) dependencia y j) actitud de lástima". 
posiciones convencionales. Sin embargo, lo que se advierte no es un carente reconocimiento de los instrumentos de derechos humanos, sino la necesidad de perfeccionamiento ${ }^{15}$ a nivel interno y de su aplicación.

Buen ejemplo de la falta de previsión en el cumplimiento de normas convencionales son los informes finales del Comité sobre los Derechos de las Personas con Discapacidad, de la onu, donde se evidencia un claro desasosiego por tal omisión en distintos países. En el caso de la República Federal Argentina se trasluce gran inquietud porque su estructura alcance un nivel pleno de accesibilidad de las personas con discapacidad en todas las provincias y municipios, así como por la falta de recursos y servicios adecuados para que puedan vivir de forma independiente y ser incluidas en la comunidad. ${ }^{16}$ En la República del Perú se observa que la Ley $n .^{\circ} 27050$, Ley General de las Personas con Discapacidad, no incluyó una definición universal sobre personas con discapacidad; por otro lado, llama la atención sobre la falta de información sobre el grado de cumplimiento de los requisitos estatales en adecuar las instalaciones públicas para que sean accesibles a las personas con discapacidad e insta al gobierno a que agilice los planes y programas para que las instalaciones, los medios de comunicación y los medios de transporte

15 Fix Zamudio, H. (2010). Los derechos humanos y su protección internacional. Perú: Editorial Grijley, p. 15.

16 Naciones Unidas, Comité de los Derechos de las Personas con Discapacidad del Alto Comisionado para los Derechos Humanos. (17 a 28 de septiembre de 2012). Observaciones finales sobre el informe inicial de la Argentina (CRPD/C/ARG/CO/1), aprobadas en su octavo periodo de sesiones. Ginebra: onu, p. 4. público les permitan el acceso. ${ }^{17}$ Por último, en la República de El Salvador, alarma la ausencia de mecanismos para vigilar el cumplimiento de las normas sobre accesibilidad, así como la falta de provisión de ayudas técnicas y de acciones para asegurar que las personas con discapacidad puedan acceder a los servicios comunitarios. ${ }^{18}$

En los distintos informes la conclusión no se centra en la falta de regulación normativa, sino en la inadecuada adopción, supervisión y ejecución de las disposiciones, lo que termina segregando aún más a la población con discapacidad, a través de barreras arquitectónicas y de comunicación. ${ }^{19}$ Ello es entendible si se tiene en cuenta que los incisos a), b) y c) del artículo III de la Convención Interamericana para la Eliminación de todas las Formas de Discriminación contras las Personas con Discapacidad ${ }^{20}$ contemplan las medidas tendientes a facilitar su integración social.

Del mismo modo, el Programa de Acción para el Decenio de las Américas por los Derechos y la Dignidad de las Personas con Discapacidad

17 Naciones Unidas, Comité de los Derechos de las Personas con Discapacidad del Alto Comisionado para los Derechos Humanos. (16 al 20 de abril de 2012). Observaciones finales sobre el informe inicial del Perú (CRPD/C/PER/O/1), aprobadas en su séptimo periodo de sesiones. Ginebra: onu, pp. 7, 13, 20 y 21.

18 Naciones Unidas, Comité de los Derechos de las Personas con Discapacidad del Alto Comisionado para los Derechos Humanos. (02 al 13 de septiembre de 2013). Observaciones finales sobre el informe inicial de El Salvador (CRPD/C/SLV/CO/1), aprobadas en su décimo periodo de sesiones. Ginebra: onu, p. 4.

19 Instituto Interamericano de Derechos Humanos, ob. cit., p. 10.

20 Cfr. Convención Interamericana para la Eliminación de Todas las Formas de Discriminación contra las Personas con Discapacidad, artículo III, incisos a), b) y c). 
(2006-2016), ${ }^{21}$ en su quinto objetivo aborda holgadamente las medidas respecto al derecho a la accesibilidad, centrándose en cinco parámetros: a) Eliminar las barreras físicas, arquitectónicas, de comunicación, información y transporte existentes, ${ }^{22}$ b) Vivir de forma independiente (derecho a la autonomía), ${ }^{23}$ c) Participación activa en sociedad, ${ }^{24}$ d) Derecho a la Vida Privada ${ }^{25}$ y e) Igualdad de condiciones, ${ }^{26}$ parámetros que se moldean también en el numeral quinto de las acciones concretas del mismo Programa de Acción y que serán materia de análisis en este estudio.

No obstante, en adición a los cinco parámetros que engloban el derecho de acceso a los servi-

21 Organización de los Estados Americanos, Grupo de Trabajo de la Comisión de Asuntos Jurídicos y Políticos. (05 de junio de 2007). Programa de Acción para el Decenio de las Américas por los Derechos y la Dignidad de las Personas con Discapacidad (2006-2016), (AG/ RES.2339 - XXXVII-O/07), aprobado en la cuarta sesión plenaria.

Organización de los Estados Americanos, Grupo de Trabajo de la Comisión de Asuntos Jurídicos y Políticos. (05 de diciembre de 2006). Leyes sobre derechos de las personas con discapacidad: vida política y pública. Comentarios al Proyecto de Programa de Acción para el Decenio de las Américas por los Derechos y la Dignidad de las Personas con Discapacidad (2006-2016). Documento presentado por la delegación de los Estados Unidos (OEA/Ser.G/CAJP/GT/DDD-20/06), p. 1.

23 Organización de los Estados Americanos, Grupo de Trabajo de la Comisión de Asuntos Jurídicos y Políticos. (05 de diciembre de 2006). Aportes al Proyecto de Programa de Acción para el Decenio de las Américas por los Derechos y la Dignidad de las Personas con Discapacidad (2006-2016), documento presentado por la delegación Argentina (OEA/Ser.G/CAJP/GT/DDD-18/06 corr.1), p. 1.

24 Organización de los Estados Americanos, Grupo de Trabajo de la Comisión de Asuntos Jurídicos y Políticos. (06 de diciembre de 2006). Comentaros al Proyecto del Programa de Acción para el Decenio de las Américas por los Derechos y la Dignidad de las Personas con Discapacidad (2006-2016), documento presentado por la Agencia Internacional para los Derechos de las Personas con Discapacidad Mental (OEA/Ser.G/CAJP/GT/DDD-22/06), p. 2.

25 Ibíd.

26

Cfr. Convención Internacional sobre los Derechos de las Personas con Discapacidad, p. 10. cios públicos de las personas con discapacidad, el artículo $9^{\circ}$ de la Convención Internacional de Ios Derechos de las Personas con Discapacidad incorpora dos medidas más que merecen ser analizadas en conjunto con los anteriores: a) ofrecer formación a todas las personas involucradas en los problemas de accesibilidad a que se enfrentan las personas con discapacidad ${ }^{27} \mathrm{y}$ b) ofrecer formas de asistencia humanas o animal e intermediarios, incluidos guías, lectores e intérpretes profesionales de la lengua de señas para facilitar el acceso a edificios y otras instalaciones abiertas al público. ${ }^{28}$

Plasmado ello, es necesario respetar las limitaciones de las personas con discapacidad y el tratamiento ius positivista de nuestro marco jurídico internacional vertido en tales parámetros. Por lo mismo, es preocupante la evasiva pública a ceñirse al marco normativo aplicable erga omnes sin discriminación, en especial al tratarse de servicios públicos cuya falta no solo priva a las personas con discapacidad de desenvolverse en sociedad, sino que faculta la comisión de hechos atentatorios contra su dignidad.

\section{2. "No discriminación" y su necesaria interrelación con el derecho a la personalidad jurídica, igualdad ante la ley y vida privada}

Abordar los parámetros antes anotados impone tratar el derecho al acceso a los servicios públicos como un todo genérico que busca proteger a

27 Ibíd., artículo $9^{\circ}$, numeral 2, inciso c).

28 Ibíd., artículo $9^{\circ}$, numeral 2, inciso e). 
las personas con discapacidad frente a aquello que les impida llevar una vida normal, sin limitación alguna. Esto exige analizar como primer eje el tratamiento no discriminatorio tanto en la normatividad interna como en las disposiciones convencionales, por tratarse de personas cuya situación de vulnerabilidad es elevada.

La Corte Interamericana de Derechos Humanos, en el caso Ximenes Lopez vs. Brasil, sobre este aspecto resaltó:

se considera que toda persona que se encuentre en una situación de vulnerabilidad es titular de una protección especial, en razón de los deberes especiales cuyo cumplimiento es necesario para satisfacer las obligaciones generales de respeto y garantía de los Derechos Humanos. [En este extremo] [I]a Corte reitera que no basta que los Estados se abstengan de violar los derechos, sino que es imperativa la adopción de medidas positivas, determinables en función de las particulares necesidades de protección del sujeto de derecho, (...) sea por su condición personal o por la situación específica en que se encuentra, como la discapacidad. ${ }^{29}$

Lineamientos que direccionan a atender no solo la necesidad del derecho a los servicios públicos como una mera obligación positiva, sino a amoldar medidas para prevenir violaciones que puedan generarse por omisión. En tal sentido,

29 Corte Interamericana de Derechos Humanos. Caso Ximenes López vs. Brasil. Sentencia de 04 de julio de 2006. Serie C n. ${ }^{\circ}$ 149, párr. 103; Caso Baldeón García vs. Perú. Sentencia de 06 de abril de 2006. (Fondo, Reparaciones y Costas. Serie C n. ${ }^{\circ} 147$, párr. 81; Caso Comunidad Indígena Sawhoyamaxa vs. Paraguay. Sentencia de 29 de marzo de 2006 (Fondo, Reparaciones y Costas). Serie C n. ${ }^{\circ}$ 146, párr. 154 y Caso de la Masacre de Pueblo Bello vs. Colombia. Sentencia 31 de enero de 2006. Serie C n. ${ }^{\circ}$ 140, párr. 111. para eliminar barreras físicas, arquitectónicas, de comunicación, información y transportes no basta con adecuar la infraestructura o facilitar los medios materiales necesarios; se requiere apoyar su implementación con personal capacitado cuya supervisión directa evite violaciones por omisión, y la realización de estudios de incidencia, prevalencia y causa de las discapacidades, ${ }^{30}$ a fin de atender sus necesidades como lo señala la Organización Panamericana de la Salud en sus aportes al Proyecto de Programa de Acción antes referido, aunque no hayan quedado consignados en su texto final.

Omitir considerar el alto grado de vulnerabilidad de las personas con discapacidad no adoptando medidas necesarias para su protección, Ilevaría consigo el incumplimiento de la obligación que tienen los Estados,

[de] abstenerse de realizar acciones que de cualquier manera vayan dirigidas, directa o indirectamente a crear situaciones de discriminación de jure o de facto ${ }^{31}$, más cuando estos se encuentran obligados a adoptar medidas positivas para revertir o cambiar situaciones discriminatorias existentes en sociedad en perjuicio de determinado grupo de personas. Implicando que el deber especial de protección del Estado debe ejercerse respecto a ac-

30 Organización de los Estados Americanos, Grupo de Trabajo de la Comisión de Asuntos Jurídicos y Políticos. (6 de diciembre de 2006). Aportes al Proyecto de Programa de Acción para el Decenio de las Américas por los Derechos y la Dignidad de las Personas con Discapacidad (2006-2016), presentados por la Organización Panamericana de la Salud (OEA/Ser.G/CAJP/GT/DDD-21/06), p. 7.

31 Corte Interamericana de Derechos Humanos. Condición jurídica y derechos de los migrantes indocumentados. Opinión Consultiva OC18/03 de 17 de septiembre de 2003. Serie A n. ${ }^{\circ}$ 18, párr. 103. 
tuaciones y prácticas de terceros que, bajo su tolerancia o aquiescencia, creen, mantengan o favorezcan las situaciones discriminatorias. ${ }^{32}$

De lo anterior se desprende uno de los criterios necesarios para no vulnerar su acceso a los servicios públicos, traducido en "no tolerar" acciones que puedan conllevar alguna situación discriminatoria. Acciones que se agravarían al no aportar los medios necesarios para el normal desenvolvimiento de las personas con discapacidad, generando dos tipos de vulneración, una positiva, por la no adaptación legal de los instrumentos internacionales, y otra material, traducida en la indebida supervisión en el cumplimiento de los preceptos legales sin discriminación, denotando actos de intolerancia.

En este contexto, el Comité sobre los Derechos de las Personas con Discapacidad de la onu, en su dictamen aprobado en el caso H. M. vs. Suecia, enuncia que

una ley que se aplique con imparcialidad puede tener un efecto discriminatorio si no se toman en consideración las circunstancias particulares de las personas a las que se aplique. EI derecho a no ser víctima de discriminación en el ejercicio de los derechos garantizados por la Convención se puede violar si los Estados, sin una justificación objetiva y razonable, no tratan

32 Corte Interamericana de Derechos Humanos: Caso Comunidad Indígena Xákmok Kásek vs. Paraguay. Sentencia del 24 de agosto de 2010. (Fondo, Reparaciones y Costas). Serie C n. ${ }^{\circ} 214$, párr. 271; Corte Interamericana de Derechos Humanos. Opinión Consultiva OC 18/03, ob. cit., 31, párr. 104; Naciones Unidas, Comité de Derechos Humanos. (11 de octubre de 1989). Observación General n. ${ }^{\circ} 18$. Comentarios generales adoptados por el Comité de Derechos Humanos, No Discriminación (U.N.Doc.HRI/GEN/1/Rev.7), aprobados en el trigésimo séptimo periodo de sesiones. de forma diferente a personas cuya situación sea considerablemente distinta. ${ }^{33}$

Supuesto en el que conviene considerar lo establecido en los artículos $1^{\circ} .1$ y $24^{\circ}$ de la CADH, sobre los que la Corte Interamericana de Derechos Humanos ha indicado que su diferencia

radica en que la obligación general del artículo 1.1 se refiere al deber del Estado de respetar y garantizar "sin discriminación" los derechos contenidos en la Convención Americana. (...) En otras palabras, si un Estado discrimina en el respeto o garantía de un derecho convencional, violará el artículo $1^{\circ} .1$ y el derecho sustantivo en cuestión. Si por el contrario la discriminación se refiere a una protección desigual de la ley interna, violará el artículo $24 .^{34}$

Anotando, además, que no solo se debe cumplir con velar por el respeto y protección de lo establecido en los artículos $1^{\circ} .1$ y $24^{\circ}$ de la CADH, sino considerar que amparar dicha protección enmarca, a su vez, el respeto de otros derechos, como el derecho a la vida, vida privada, igualdad, entre otros, que son el cimiento no solo para garantizar los derechos convencionales advertidos en su contenido esencial, sino que evitan la implementación de leyes internas discriminatorias frente a la discapacidad. De esta suerte, es imposible desligar la responsabilidad

33 Comunicación $n .^{\circ} 3 / 2011$, dictamen aprobado en su séptimo periodo de sesiones (CRPD/C/7/D/3/2011), 16 al 27 de abril de 2012, párr. 8.3.

34 Corte Interamericana de Derechos Humanos: Caso Aptiz Barbera y otros (Corte Primera de lo Contencioso Administrativo) vs. Venezuela. Sentencia de 05 de agosto de 2008. (Excepción Preliminar, Fondo, Reparaciones y Costas). Serie C n. ${ }^{\circ} 182$, párr. 209; Corte Interamericana de Derechos Humanos. Propuesta de modificación a la Constitución Política de Costa Rica, relacionada con la naturalización. Opinión Consultiva OC-4-84, de 19 de enero de 1984 . Serie A n. ${ }^{\circ} 4$, párrs. 53 y 54. 
generada por la aprobación de una ley que sea discriminatoria, de los derechos convencionales asumidos que también serían materia de violación. Por ejemplo, el promulgar una ley que elimine barreras físicas, arquitectónicas y de comunicación en una entidad pública lleva a pensar que se está poniendo en aplicación normas convencionales erga omnes sobre personas con discapacidad. Sin embargo, si lo dispuesto en dicha ley no se ejecuta, no se reglamenta o no se capacita al personal indicado para guiar tales labores, también se estarían vulnerando los derechos de las personas con discapacidad. En este entender, es inverosímil desligar la violación al artículo $24^{\circ}$ del $1^{\circ} .1$ de la CADH.

En adición a ello, se vulneraría incluso el derecho a la personalidad jurídica, establecido en el artículo $12^{\circ}$ de la Convención sobre los Derechos de las Personas con Discapacidad, por el que se tiene la obligación de reconocer que personas con discapacidad "tienen capacidad jurídica en igualdad de condiciones con los demás en todos los aspectos de la vida", ${ }^{35}$ esto es, el derecho de toda persona a que se le reconozca en cualquier parte como sujeto de derechos y obligaciones. ${ }^{36}$ Ergo, la violación de aquel reco-

35 Comité sobre los Derechos de las Personas con Discapacidad de las Naciones Unidas. Caso Zsolt Buydosó y otros vs. Hungría. Comunicación n. ${ }^{\circ}$ /2011, dictamen aprobado en su décimo periodo de sesiones, (CRPD/C/10/D/4/2011), 20 de septiembre de 2013, párr. 9.5.

36 Corte Interamericana de Derechos Humanos: Caso Bámaca Velásquez vs. Guatemala. Sentencia de 25 de noviembre de 2000. (Fondo, Reparaciones y Costas). Serie C n. ${ }^{\circ} 70$, párrs. 12 y 179; Caso de las Niñas Yean y Bosico vs. República Dominicana. Sentencia de 8 de septiembre de 2005. (Fondo, Reparaciones y Costas). Serie C n. ${ }^{\circ} 130$, párr. 176; Caso la Cantuta vs. Perú. Sentencia de 29 de noviembre de 2006. (Fondo, Reparaciones y Costas). Serie C n. ${ }^{\circ} 173$, párr. 120 y Caso Ticona Estrada y otros vs. Bolivia. Sentencia de 27 de noviembre de 2008. (Fondo, Reparaciones y Costas). Serie C n. ${ }^{\circ} 191$. nocimiento supone desconocerles, en términos absolutos, la posibilidad de ser titulares de esos derechos y deberes ${ }^{37}$, puesto que al mantener barreras físicas, arquitectónicas, de comunicación, información y transporte se les limita el goce de vivir en forma independiente, así como de participar activamente en sociedad en igualdad de condiciones tanto formales como materiales, no cumpliéndose con la obligación de procurar los medios y condiciones para que ese derecho pueda ser ejercido libre y plenamente por sus titulares, ${ }^{38}$ o con la obligación de no vulnerar dicho derecho ${ }^{39}$.

Por su parte, el Comité de Ministros del Consejo de Europa, el 5 de abril de 2006, aprobó el Plan de Acción Europeo para promover los derechos y la plena participación de las personas con discapacidad en sociedad, que establece en su línea de acción n. ${ }^{\circ}$ 12: "las personas con discapacidad constituyen un sector heterogéneo de la población, pero todos tienen en común, en mayor o menor medida, la existencia de garantías adicionales con el fin de disfrutar de sus derechos a la participación plena en la sociedad en pie de igualdad con los demás miembros" 40

37 Corte Interamericana de Derechos Humanos: Caso Bámaca Velásquez vs. Guatemala, supra nota 34, párr. 179; Caso Comunidad Indígena Sawoyamaxa vs. Paraguay. Sentencia de 29 de marzo de 2006. (Fondo, Reparaciones y Costas). Serie C n. ${ }^{\circ}$ 146, párr. 188.

38 Corte Interamericana de Derechos Humanos: Caso Ibsen Cárdenas e Ibsen Peña vs. Bolivia. Sentencia de 01 de setiembre de 2010. (Fondo, Reparaciones y Costas). Serie C n. ${ }^{\circ} 127$, párr. 97; Caso Torres Millacura y otros vs. Argentina. Sentencia de 26 de agosto de 2011. (Fondo, Reparaciones y costas), párr. 105

39 Corte Interamericana de Derechos Humanos: Caso de las Niñas Yean y Bosico vs. República Dominicana, supra nota 34, párr. 179; Caso Ibsen Cárdenas e Ibsen Peña vs. Bolivia, supra nota 36, párr. 97.

40 Comité de Ministros del Consejo de Europa. (5 de abril de 2006). Recomendación Rec. (2006) 5 del Comité de Ministros a los Estados 
[subrayas añadidas]. Resaltándose la necesidad no solo de exigir igualdad de oportunidades para las personas con discapacidad, sino de garantizar la igualdad de resultados en las acciones adoptadas. ${ }^{41}$

Visto el alcance del derecho a la personalidad jurídica e igualdad ante la ley merece analizarse si limitar el acceso a los servicios públicos puede ser objeto de distinción por parte de los Estados, al haber gran preocupación por la basta y gastada opinión de que la distinción siempre lleva consigo una discriminación. Aclarando tal panorama, debe entenderse que "no toda distinción de trato puede considerarse ofensiva por sí misma, de la dignidad humana", ${ }^{42}$ pues conforme lo señala el Tribunal Europeo de Derechos Humanos, la distinción es discriminatoria cuando "carece de justificación objetiva y razonable". ${ }^{43}$

Miembros sobre el Plan de Acción del Consejo de Europa para la Promoción de Derechos y la Plena Participación de las Personas con Discapacidad en la Sociedad: mejor calidad de vida de las personas con discapacidad en Europa 2006-2015 (aprobada durante la 961 reunión de Delegados de Ministros), p. 63; European Court of Human Rights. Case of Dordevic v. Croatia. Application No. 41526/10. Judgment Strasbourg of 24 July, 2012, párr. 76.

Organización de los Estados Americanos, Grupo de Trabajo de la Comisión de Asuntos Jurídicos y Políticos (20 de noviembre de 2006). Leyes sobre derechos de las personas con discapacidad: vida política y pública. Aportes al Proyecto de Programa de Acción para el Decenio de las Américas por los Derechos y la Dignidad de las Personas con Discapacidad (2006-2016). Documento presentado por la Delegación de los Estados Unidos, (OEA/Ser.G/CAJP/GT), p. 2. "Se enfoca lo citado por el Grupo de Trabajo contrario sensu a sus aportes, dado que señalan: "La Ley estadounidense exige la igualdad de oportunidades, pero no garantiza la igualdad de resultados".

Corte Interamericana de Derechos Humanos. OC-4-84, op. cit., 34, párr. 56.

43 European Court of Human Rights: Case Willis v. The United Kingdom. Application No. 36042/97, Judgment Strasbourg of 11 June 2002, para. 39; Case of Wessels-Bergervoet v. The Netherlands. Application No. 34462/97, Judgment Strasbourg of 4 June 2002, para. 46; Case Petrovic v. Austria. Application No. 20458/92, Judgment Strasbourg of
Justificación objetiva y razonable que tiene dos variantes, una progresiva o positiva y otra regresiva o abusiva. Para el caso en análisis resulta viable establecer distinciones progresivas a las personas con discapacidad, siempre y cuando dicha distinción únicamente sea en referencia al medio para acceder a algún servicio público garantizado y no en cuanto a limitar su acceso, afirmando la protección de las personas con discapacidad en igualdad y efectividad.

A modo de ejemplo: en el caso de las barreras arquitectónicas, de comunicación, información y transporte existentes, puede establecerse una distinción en el no uso por parte de las personas con discapacidad de determinados medios de acceso, por no considerarse adecuados para proteger y salvaguardar su integridad, siempre y cuando se ofrezcan en paralelo otros igualmente eficaces y plausibles. En tal contexto se hablaría de una distinción progresiva o positiva, al ser una limitación que asegura el cumplimiento de normas convencionales.

Es de anotar que el derecho a la igualdad ante la ley y la no discriminación pertenece al ius cogens. ¿Qué comprende ello? Que sobre él descansa todo el andamiaje jurídico del orden público nacional e internacional y es un principio fundamental que permea todo ordenamiento jurídico. ${ }^{44} \mathrm{En}$ consecuencia, es intolerable que personas con

27 of March, 1998, Reports 1998-II, para. 30; Case "relating to certain aspects of the laws on the use of languages in education in Belgium" v. Belgium, Application No.1474/62, Judgment Strasbourg of 23 July 1968, para.10.

44 Corte Interamericana de Derechos Humanos. Opinión Consultiva OC18-03, ob. cit., 31, párr. 101. 
discapacidad sean a menudo objeto de discriminación por su condición. De ahí que los Estados deban adoptar las medidas de carácter legislativo, social, educativo, laboral o de cualquier otra índole, necesarias para que toda discriminación asociada con las discapacidades sea eliminada, y para propiciar la plena integración de esas personas a la sociedad. ${ }^{45}$ Queda así clarificado que el principio de no discriminación es la base para la formulación de políticas gubernamentales diseñadas para ofrecer igualdad de oportunidades a las personas con discapacidad. ${ }^{46}$

Asegurar de este modo la igualdad de oportunidades, como base del derecho de las personas con discapacidad a acceder a servicios públicos, arrastra consigo la protección de una gama de derechos antes abordados, que acorde con la Recomendación n. ${ }^{\circ} 6$ del Comité de Ministros del Consejo de Europa deben "garantizar el derecho de las personas con discapacidad a una vida independiente y la plena integración en la sociedad, y reconocer el deber de la sociedad para que esto sea posible" así como la "igualdad de oportunidades para que tengan tanta movilidad como sea posible, [es decir] el acceso a edificios y medios de transporte, los que juegan un papel activo en la sociedad para su participación en la vida económica, social, de ocio, las actividades recreativas y culturales", ${ }^{47}$

45 Corte Interamericana de Derechos Humanos. Caso Furlan y Familiares vs. Argentina. Supra nota 6, párr. 135.

46 Cfr. Convenio Europeo para la Protección de los Derechos Humanos y de las Libertades Fundamentales, aprobado por el Comité de Ministros de Europa el 05 de abril de 2006, Línea de Acción n. ${ }^{\circ} 12$.

47 Comité de Ministros del Consejo de Europa. (9 de abril de 1992). Recomendación R (92)6, aprobada por la Asamblea Parlamentaria del Consejo de Europa. garantizándoles, independientemente de la edad, naturaleza y origen de su discapacidad, el ejercicio efectivo del derecho a la autonomía, su integración social y la participación en la vida de la comunidad, a través de medidas, incluidas las ayudas técnicas con el objeto de superar las barreras de comunicación, permitiéndoles el transporte, vivienda, actividades culturales y de ocio. $^{48}$

Resulta sustancial, aún más, enfatizar el derecho a la vida privada de las personas con discapacidad, amparado en el artículo $11^{\circ}$ de la CADH "Protección de la Honra y de la Dignidad", abordado también por la Corte Interamericana de Derechos Humanos en su última sentencia en al caso J vs. Perú, de cuyos argumentos se confirma que este derecho incluye la protección a la vida privada. ${ }^{49}$

En cuanto a la autodeterminación y autonomía en la participación, el Programa de Acción para el Decenio de las Américas (2006-2016), tomando el aporte señalado por la Agencia Internacional para los Derechos de las Personas con Discapacidad Mental, enuncia como acciones concretas a realizar por los Estados el "Crear y fortalecer una cultura de percepción positiva del potencial humano, autodeterminación e independencia individual, conocimiento,

48 Comité de Ministros del Consejo de Europa. (07 de mayo de 1992). Recomendación n. ${ }^{\circ} 1185$ (1992) sobre las Políticas de Rehabilitación para Discapacitados, aprobada por la Asamblea Parlamentaria del Consejo de Europa, párrs. 3, 21 y 22.

49 Corte Interamericana de Derechos Humanos. Caso J. vs. Perú. Sentencia de 27 de noviembre de 2013. (Excepción Preliminar, Fondo, Reparaciones y Costas). Serie C n. ${ }^{\circ} 275$, párr. 367; Caso Masacre de Ituango vs. Colombia. Sentencia 01 de julio de 2006. Serie C n. ${ }^{\circ} 148$, párr. 166. 
méritos, habilidades y aportes a la sociedad de las personas con discapacidad", ${ }^{50}$ reconociendo siempre su derecho a ejercer control sobre sus propias decisiones. ${ }^{51}$

De esta manera, poner trabas legislativas materializadas en obras e infraestructura de los servicios públicos, más que limitar, viola el derecho de las personas con discapacidad a que se respete su vida privada, quedando esta al arbitrio del actuar social, soslayando de paso sus posibilidades de potenciar sus habilidades en pro de su desarrollo profesional y personal. Aspecto que iría en contra de lo establecido en el artículo $11^{\circ} .2$ de la $\mathrm{CADH}$, en el entender que el derecho a la vida privada no es un derecho absoluto y, por lo tanto, puede ser restringido por los Estados siempre que las injerencias no sean abusivas o arbitrarias. El acceso a servicios básicos para poder movilizarse y para realizar actividades recreativas, sociales, culturales, no persiguen un fin ilegítimo, ni son innecesarias para una sociedad democrática, ${ }^{52}$ contrario sensu a los elementos que tendrían que desarrollarse para que se establezcan restricciones al derecho a la vida privada de las personas con discapacidad. Muy por el contrario, aseguran el desarrollo de sus derechos sin tapujos legales o sociales. Lo que sí es ilegal y antidemocráti-

50 Organización de los Estados Americanos, Grupo de Trabajo de la Comisión de Asuntos Jurídicos y Políticos. Aportes al Proyecto de Programa de Acción..., ob. cit., 21, p. 6.

51 lbíd., p. 3.

52 Corte Interamericana de Derechos Humanos: Caso Tristán Donoso vs. Panamá. Sentencia del 27 de enero de 2009. (Excepciones Preliminares, Fondo, Reparaciones y Costas). Serie C n. ${ }^{\circ} 193$, párr. 117; Caso Escher y otros vs. Brasil. Sentencia de 06 de julio de 2009. Serie C n. ${ }^{\circ} 200$, párr. 116. co es someter a discriminación a un sector de la población como las personas con discapacidad, sin considerar su situación particular, más cuando el impedimento para acceder a los servicios públicos proviene del Estado, vía una política general o una medida que tiene un efecto desproporcionalmente perjudicial, aún sin estar dirigida específicamente a dicho grupo. ${ }^{53}$

De ello se deriva la responsabilidad por omisión, siendo obligación de los Estados propender por la inclusión de las personas con discapacidad en igualdad de condiciones, oportunidades y participación en todas las esferas de la sociedad, ${ }^{54}$ y velar porque las barreras arquitectónicas, físicas, de comunicación y de transporte existentes, entre otras, sean desmanteladas, para poder atender el derecho de las personas con discapacidad desde los cinco parámetros advertidos anteriormente en este estudio. Urge, de este modo, promover prácticas estatales de inclusión social y adoptar medidas de diferenciación positiva para reconocer dichas barreras. ${ }^{55}$

53 European Court of Human Rights: Case DH and others v. Czech Republic. Application $N^{\circ} 57325 / 00$, Judgment Strasbourg of 13 November 2005, para. 175; Case Hugh Jordan v. United Kingdom. Application n. ${ }^{\circ}$ 24746/94, Judgment Strasbourg of 04 May 2001, para. 154.

54 Corte Interamericana de Derechos Humanos. Caso Furlan y Familiares vs. Argentina, supra nota 6, párr. 134. Naciones Unidas. Normas uniformes sobre la igualdad de oportunidades para las personas con discapacidad, ob. cit., artículo 5.

55 Corte Interamericana de Derechos Humanos. Caso Artavia Murillo y otros "fecundación in vitro" vs. Costa Rica. Sentencia de 28 de noviembre de 2012. (Excepciones, Fondo, Reparaciones y Costas). Serie C n. ${ }^{\circ} 257$, párr. 292. Naciones Unidas. Comité de Derechos Económicos, Sociales y Culturales. Observación General $n .^{\circ} 5$, párr. 13. 


\section{3. "Vida", derecho impostergable de las personas con discapacidad}

Analizado el concepto de discapacidad, el problema de las personas con discapacidad para acceder a los servicios públicos y los derechos afectados por las omisiones en tal sentido, es momento de aterrizar en el derecho a la vida, que vitaliza el derecho de las personas con discapacidad.

Quizás se pregunte: ¿por qué primero analizar la vulneración del derecho a la personalidad jurídica, igualdad ante la ley y vida privada sin antes analizar el derecho a la vida? La respuesta es simple, de no conocer en su génesis la necesidad en la regulación normativa, entiéndase el estatus de protección de las personas con discapacidad (positiva) y las necesidades subjetivas que emergen y requieren ser satisfechas en sociedad por las personas con discapacidad en materia de servicios públicos (materializadas en sus derechos), terminará por no garantizarse un derecho vital, consignado no solo en los convenios internacionales e interamericanos, sino en las propias constituciones políticas de cada Estado, como es el derecho a la vida, base para el desarrollo de normas fundamentales, y que de no ampararse generaría su muerte civil ${ }^{56}$ arriesgando su integridad física.

56 "Antigua situación jurídica de la persona con vida a la que, por efecto de una pena, se le privaba de toda clase de derechos civiles y políti$\cos$, y hasta del agua y el fuego en la típica expresión romana 'aque et ignis interdictio'. La denominación procede, al parecer, de una Constitución de Federico II de Prusia, en la cual se preceptuó que a los sometidos a tales sanciones se les considerara como muertos, cual 'cadáveres vivientes"'. Cabanellas, G. (1981). Diccionario Enciclopédico de Derecho Usual. (20 ed.). Tomo V. Argentina: Editorial Heliasta, p. 476.
Fundamentemos tal afirmación. La Convención sobre los Derechos de las Personas con Discapacidad no crea ningún derecho nuevo, su logro más notable es desarrollar a profundidad los derechos humanos reconocidos a todos, con énfasis en las personas con discapacidad, y establecer las obligaciones mínimas para el Estado, la sociedad y la familia. ${ }^{57}$ No puede alegarse, por tanto, que sea a partir de la aprobación de la mencionada Convención que los derechos de las personas con discapacidad empezaron a ser protegidos, más aún, cuando la Declaración Americana de los Derechos y Deberes del Hombre, adoptada en 1948, en el artículo XVI ya los reivindicaba: "Toda persona tiene derecho a la seguridad social que le proteja contra las consecuencias de la desocupación, de la vejez y de la incapacidad que, proveniente de cualquier otra causa ajena a su voluntad, la imposibilite física o mentalmente para obtener los medios de subsistencia". 58

Estando salvaguardados tales derechos de manera inexorable, es de recalcar que el derecho a la vida: "es un prerrequisito para el disfrute de todos los demás derechos humanos. (...) no [siendo] admisibles enfoques restrictivos del mismo (...) comprende (...) que no se le impida el acceso a las condiciones que le garanticen una existencia digna. [Estando] Los Estados [en] la obligación de garantizar la creación de las con-

57 Trömel, S. (2008). La Convención sobre los derechos de las personas con discapacidad y los retos para su implementación. (Ponencia). Foro Convención sobre los Derechos de las Personas con Discapacidad realizado por la Universidad de los Andes, Bogotá.

58 Corte Interamericana de Derechos Humanos. Caso Furlan y Familiares vs. Argentina. Supra nota 6, párr. 128. 
diciones que se requieran para que no se produzcan violaciones de ese derecho básico".59 [Énfasis propio].

En razón de ello es pertinente determinar el problema vigente en la cotidianidad de las personas con discapacidad, al encontrar en el espacio público trabas de comunicación, arquitectónicas, de información, físicas y de transporte, que limitan no solo su derecho de acceso a diversos servicios públicos, sino que atentan contra su propia integridad física, poniendo en peligro su vida. Además, señalar que "el derecho a la vida juega un papel fundamental en la Convención Americana, por ser el corolario esencial para la realización de los demás derechos". ${ }^{60}$ Obligación que exige garantizar las condiciones requeridas para que no se produzcan violaciones de ese derecho inalienable $y$, en particular, el deber de impedir que los agentes del atenten contra él. ${ }^{61}$ Dicha garantía no se asegura con el cumplimiento pasivo de la norma, requiere ser plasmada integralmente en los espacios públicos, sin excluir a ninguna persona, independiente del tipo de discapacidad, acorde con la cla-

59 Comisión Interamericana de Derechos Humanos. Caso 12.308, Manoel Leal de Olivera vs. Brasil. Informe n. ${ }^{\circ} 37 / 10,17$ de marzo de 2010, párr. 78; Corte Interamericana de Derechos Humanos. Caso de los "Niños de la Calle" (Villagrán Morales y otros) vs. Guatemala. Sentencia de 19 de noviembre de 1999. Serie $\mathrm{C}$ n. ${ }^{\circ}$ 63, párr. 144.

60 Comisión Interamericana de Derechos Humanos: Caso Leydi Dayán Sánchez vs. Colombia. Informe n. ${ }^{\circ} 43 / 09$; Caso 12.009. (Fondo). 23 de julio de 2008, párr. 44; Corte Interamericana de Derechos Humanos. Caso de los Hermanos Gómez Paquiyauri vs. Perú. Sentencia de 08 de julio de 2004. (Fondo, Reparaciones y Costas). Serie C n. ${ }^{\circ} 110$, párr. 128; Caso Myrna Mack Chang vs. Guatemala. Sentencia de 25 de noviembre de 2003. (Fondo, Reparaciones y Costas). Serie C n. ${ }^{\circ}$ 101, párr. 152.

61 Corte Interamericana de Derechos Humanos. Caso Juan Humberto Sánchez vs. Honduras. Sentencia de 07 de junio de 2003. (Excepción Preliminar, Fondo, Reparaciones y Costas). Serie C n. ${ }^{\circ}$ 99, párr. 110. sificación dada por la oms, pues los Estados en su condición de garantes de este derecho están obligados a prevenir situaciones que pudieran conducir, por acción u omisión, a la afectación de aquel. ${ }^{62}$

Prevención que se deriva de la obligación de garantizar las condiciones que se requieran para que no se produzcan violaciones de ese derecho inalienable ${ }^{63}$ que es la vida. Resulta preocupante que la mayoría de adecuaciones en la infraestructura y en el acceso a servicios públicos para personas con discapacidad se limiten a la construcción de rampas, puertas de acceso más amplias para permitir la movilidad de las personas en sillas de ruedas, pasamanos y otros ajustes técnicos circunscritos a la movilidad, desconociendo las necesidades de los demás tipos de discapacidades, en especial las sensoriales, como las de los sordos, los ciegos y los sordomudos, para quienes el braille en los avisos y las comunicaciones, la información sonora y la presencia de guías e intérpretes de la lengua de señas harían una gran diferencia en su vida cotidiana. ${ }^{64}$

62 Corte Interamericana de Derechos Humanos. Caso de los Hermanos Gómez Paquiyauri vs. Perú, supra nota 58, párr. 124.

63 Corte Interamericana de Derechos Humanos: Caso Luna López vs. Honduras. Sentencia de 10 de octubre de 2013. (Fondo, Reparaciones y Costas). Serie C n. ${ }^{\circ}$ 269, párr. 117; Caso Villagrán Morales y otros (Niños de la Calle) vs. Guatemala. Sentencia de 19 de noviembre de 1999. (Fondo). Serie C n. ${ }^{\circ} 63$, párr. 144; Caso Masacre de Santo Domingo vs. Colombia. Sentencia de 30 de noviembre de 2012. (Excepciones Preliminares, Fondo y Reparaciones). Serie $\mathrm{C} \mathrm{n} .{ }^{\circ} 259$, párr. 190.

64 Correa-Montoya, L. (Enero-junio de 2009). Panorama de la protección jurisprudencial de los derechos humanos de las personas con discapacidad en Colombia. Vniversitas, 118, 115-139, p. 10. 
El deber de los Estados de prevenir las violaciones a dicho derecho abarca "todas aquellas medidas de carácter jurídico, político, administrativo y cultural que promuevan la salvaguarda de los derechos humanos" ${ }^{65}$, siendo suficiente para establecer su responsabilidad "demostrar que se han verificado acciones $u$ omisiones que hayan permitido la perpetración de esas violaciones o que exista una obligación del Estado que haya sido incumplida". ${ }^{66}$

La Corte Constitucional de Colombia en su sentencia T-288 de 1995, advierte que

existen por lo menos dos tipos de situaciones que pueden constituir un acto discriminatorio contrario al derecho a la igualdad de los discapacitados. Por un lado, la conducta, actitud o trato consciente o inconsciente, dirigido a anular o restringir sus derechos, libertades y oportunidades, sin justificación objetiva y razonable. Por otro lado, el acto discriminatorio consistente en una omisión injustificable en el trato especial a que tienen derecho los discapacitados, la cual trae como efecto directo su exclusión de un beneficio, ventaja u oportunidad. ${ }^{67}$

Dicha discriminación en el hacer y no hacer repercute en la protección del derecho a la vida de las personas con discapacidad, pues el no

65 Corte Interamericana de Derechos Humanos: Caso González y otras ("Campo Algodonero") vs. México. Sentencia de 16 de noviembre de 2009. (Excepción Preliminar, Fondo, Reparaciones y Costas). Serie C n. ${ }^{\circ}$ 205, párr. 252; Caso Velásquez Rodríguez vs. Honduras. Sentencia de 29 de julio de 1988. (Fondo). Serie C n. ${ }^{\circ}$ 4, párr. 166.

Corte Interamericana de Derechos Humanos. Caso Masacre de Santo Domingo vs. Colombia, supra nota 61, párr. 162.

67 Corte Constitucional de Colombia. Sentencia T-288/1995 de 5 de julio de 1995. M. P.: Eduardo Cifuentes Muñoz. brindar un adecuado sistema de prevención de riesgos en edificaciones o en aquellas por construirse, así como en los medios de comunicación y de acceso a vías públicas, pone en peligro por omisión el derecho a la vida, cuya violación agrava la responsabilidad del Estado que omitió ejecutar materialmente aquellos dispositivos necesarios para su protección, teniendo como consecuencia la anulación de sus derechos.

En esta dirección, el Tribunal Constitucional del Perú indicó, a tenor de los artículos $7^{\circ}$ y $23^{\circ}$ de su Constitución Política, y del artículo $18^{\circ}$ del Protocolo Adicional de la Convención Americana de Derechos Humanos en materia de Derechos Económicos, Sociales y Culturales o Protocolo de San Salvador que "toda persona afectada por una disminución en sus capacidades físicas o mentales tiene derecho a recibir una atención especial con el fin de alcanzar el máximo desarrollo de su personalidad y es protegida especialmente por el Estado; con el respeto a su dignidad personal y laboral". 68

Por ello, es justamente de las deficiencias en infraestructura, transporte y acceso a los servicios públicos de donde se desprende la falta de atención especial a las personas con discapacidad, y donde se les vulnera el derecho a la vida por dos razones: la evasiva en adecuar la infraestructura y sistemas para un acceso equitativo y eficaz como lo ordenan las disposiciones convencionales, y la falta de control en los mecanismos reglamentados pero que no se ejecu-

68 Tribunal Constitucional del Perú. Acción de Amparo interpuesta por Irene Calderón García contra la Empresa Municipal Administradora de Peaje de Lima (EMAPE). Expediente n. ${ }^{\circ} 00035-2010-P A-T C$, párr. 8. 
tan, sea por falta de personal o por inadecuada supervisión. Con ello se está poniendo en riesgo a más de 1000 millones de personas (un 15\% de la población mundial) que padecen alguna forma de discapacidad; de ellas, entre 110 y 190 millones de adultos tienen dificultades considerables para desenvolverse normalmente en sociedad $^{69}$ y requieren un trato especial y diferenciado que les asegure su derecho a la vida, que es la garantía para el desarrollo de todo el corolario de derecho que ya hemos explicado: vida privada, personalidad jurídica e igualdad, etc.

Para finalizar este apartado es importante anotar lo señalado por la Corte Constitucional de Colombia en su sentencia T-595-03, en relación con la accesibilidad al sistema público de transporte: "el ámbito de protección de la libertad de locomoción de una persona discapacitada contempla la posibilidad de acceder al sistema de transporte público básico de una ciudad en condición de igualdad, es decir, sin tener que soportar limitaciones que supongan cargas excesivas". ${ }^{70}$ Lo anterior implica adoptar medidas pertinentes para desarrollar, promulgar y supervisar la aplicación de normas mínimas y directrices sobre la accesibilidad a las instalaciones y los servicios abiertos al público o de uso público, y asegurar que las entidades privadas que proveen instalaciones y servicios abiertos al público o de uso público tengan en cuen-

69 Organización Mundial de la Salud. (Septiembre de 2013). Nota Descriptiva $n .^{\circ} 352$. Recuperado de: http://www.who.int/mediacentre/factsheets/fs352/es/.

70 Corte Constitucional de Colombia. Sentencia T-595-2003 de 17 de julio de 2003. M. P.: Inés Vargas Fernández. ta todos los aspectos necesarios para hacerlos accesibles a las personas con discapacidad; ${ }^{71}$ normas mínimas que de ser obstaculizadas por decisiones políticas y legales tendrían consecuencias nefastas para su integridad física.

La obligación del Estado en materia de garantizar los derechos de los discapacitados rige tanto al interior de su estructura orgánica (en los distintos niveles de organización territorial) como en supervisar el cumplimiento de las disposiciones por parte de las entidades públicas y privadas responsables de los servicios públicos y de asegurar el acceso a ellos de las personas con discapacidad. Es también obligación del Estado prevenir que terceros vulneren los bienes jurídicos protegidos, ${ }^{72}$ garantizando la tutela del derecho a la vida y su normal desenvolvimiento a través de servicios públicos accesibles.

\section{CONTROL DE CONVENCIONALIDAD Y EL DERECHO AL ACCESO A SERVICIOS PÚBLICOS}

Analizados los problemas que enfrentan las personas con discapacidad en el acceso a los servicios públicos, a continuación se aborda el control de convencionalidad anunciado líneas atrás.

71 Cfr. Naciones Unidas, Comité sobre los Derechos de las Personas con Discapacidad. Caso Szilvia Nyusti y Péter Takács vs. Hungría. Comunicación n. ${ }^{\circ} 1 / 2010$. Dictamen aprobado en su noveno periodo de sesiones. (CRPD/C/9/D/1/2010), 15 a 19 de abril de 2013, párr. 9.4 .

72 Corte Interamericana de Derechos Humanos: Caso de la Masacre de Mapiripan vs. Colombia. Sentencia de 15 de septiembre de 2005. (Fondo, Reparaciones y Costas). Serie C n. ${ }^{\circ} 134$, párr. 111; Caso Suárez Peralta vs. Ecuador. Sentencia de 21 de mayo de 2013. (Excepciones Preliminares, Fondo, Reparaciones y Costas). Serie C n. ‥ 261, párr. 129; Caso Luna López vs. Honduras, supra nota 61, párr. 120. 
La Declaración Americana de los Derechos y Deberes del Hombre, aprobada en la Novena Conferencia Interamericana realizada en Bogotá el 02 de mayo de 1948, y que antecedió a la Declaración Universal de Derechos Humanos, marcó el inicio de la supra nacionalización de los derechos humanos en el continente americano. Si bien por tratarse de una declaración sus efectos no son vinculantes, la CADH aprobada en San José de Costa Rica el 22 de noviembre de 1969 -también conocida como Pacto de San José-, en vigencia desde el 18 de julio de 1978, sí tiene dicho carácter. ${ }^{73}$

Los deberes convencionales de la CADH son supervisados a través de sus organismos interamericanos, preventivamente o al momento en que se vea vulnerado un derecho, previo agotamiento de los recursos internos, con el fin de determinar la posible responsabilidad del Estado. Es aquí donde el control difuso de convencionalidad, entendido como el control propio del Estado en cuanto a sujetar las normas internas a las convencionales asumidas, aparece como una herramienta sumamente eficaz para el respeto, la garantía y la efectivización de los derechos descritos por el Pacto de San José, ${ }^{74}$ que como norma del derecho internacional de los derechos humanos debe implementarse al interior de los Estados y tener la necesaria aten-

73 Cfr. Vidal Ramírez, F. (Julio 2009). El agotamiento de la jurisdicción interna y el acceso a la jurisdicción supranacional. Gaceta Constitucional, 19, p. 16

74 Cfr. Sagüs, N. (2010). Obligaciones internacionales y control de convencionalidad. Estudios Constitucionales, 8(1), 118. ción y aplicación por los poderes judiciales de la región. ${ }^{75}$

En este contexto, la CADH, la Convención Interamericana para la Eliminación de todas las Formas de Discriminación contra las Personas con Discapacidad y la Convención Internacional sobre los Derechos de las Personas con Discapacidad, así como los planes y programas derivados de dichas normas convencionales, son de aplicación inmediata (self executing) tan pronto pasan a formar parte de la normativa interna. En consecuencia, el ejercicio interpretativo que realice todo órgano jurisdiccional para determinar el contenido constitucional en materia de derechos fundamentales debe estar obligatoriamente informado por las disposiciones de los tratados internacionales de derechos humanos y la jurisprudencia al respecto. ${ }^{76}$ Como bien lo precisó el expresidente de la Corte Interamericana de Derechos Humanos, doctor Diego García-Sayán, “la armonización del derecho interno y de la actuación de las autoridades del Estado con las estipulaciones de un tratado como la Convención Americana sobre Derechos Humanos es uno de los elementos centrales del objeto y fin de un tratado como el mencionado", ${ }^{77}$ no

75 Cfr. Castilla, K. (2011). El control de convencionalidad: un nuevo debate en México a partir de la sentencia del Caso Radilla Pacheco. Anuario Mexicano de Derecho Internacional, vol. XI, p. 596.

76 Cfr. Castillo Alva, J. (Septiembre de 2012). La validez de una sentencia penal. Acerca de la calificación de un hecho como grave violación a los derechos humanos: entre el respeto a las normas internas y el cumplimiento de la jurisprudencia de la Corte IDH. A propósito de la sentencia del caso Barrios Altos (Primera parte). Gaceta Constitucional, 39, p. 68.

77 Cfr. García-Sayán, D. (Abril de 2009). Justicia interamericana y tribunales nacionales. En Aspectos del derecho procesal constitucional. Estudios en homenaje a Héctor Fix-Zamudio en sus cincuenta años como investigador del derecho (colaboraciones peruanas). Perú: Editorial Moreno, p. 362. 
pudiendo invocarse situaciones excepcionales en perjuicio de los derechos humanos. De esta forma, los jueces y todos los órganos vinculados a la administración de justicia en los distintos niveles están sometidos a las normas convencionales y deben velar porque sus disposiciones no se vean mermadas por la aplicación de medidas contrarias a su objeto y fin. En nuestro caso, están en la obligación de ejercer ex officio un control difuso de convencionalidad entre las normas internas, ${ }^{78}$ la CADH y las normas especiales en materia de protección de las personas con discapacidad, en el marco de sus respectivas competencias y de las regulaciones procesales correspondientes. En definitiva, el Estado es quien responde por los actos de los órganos del poder ejecutivo, legislativo y judicial, ${ }^{79}$ en acatamiento de un principio que, si bien no es convencional está recogido y debe ser acatado en virtud del ius cogens. ${ }^{80}$

Pero es en el marco de la $\mathrm{CADH}$, que recoge el respeto y garantía de una multiplicidad de derechos de las personas con discapacidad al acceso a servicios públicos, y más específicamente en el ámbito regional la Convención Interamericana para la Eliminación de todas las Formas de Discriminación contra las Personas con Dis-

78 Corte Interamericana de Derechos Humanos. Caso Chocrón Chocrón vs. Venezuela. Sentencia de 01 de julio de 2011. (Excepción Preliminar, Fondo, Reparaciones y Costas). Serie $\mathrm{C}$ n. ${ }^{\circ}$ 227, párr. 164.

79 Corte Interamericana de Derechos Humanos. Caso "La Última Tentación de Cristo" (Olmedo Bustos y otros) vs. Chile. Sentencia de 5 de febrero de 2001. (Fondo, Reparaciones y Costas). Serie C n. ${ }^{\circ} 73$, párr. 72 .

80 Torres Zúñiga, N. (Julio, 2009). Las relaciones entre la Corte Interamericana de Derechos Humanos y los tribunales locales. La incorporación de la jurisprudencia internacional en el marco de la resolución de conflictos por jueces nacionales. Gaceta Constitucional, 19, p. 41. capacidad, que resulta necesario esclarecer los alcances del control difuso de convencionalidad.

Entender el contexto social, como punto de partida, ayuda a develar los componentes que deben ser analizados por los Estados al momento de adecuar las disposiciones convencionales y tratados internacionales por ellos ratificados, al ordenamiento interno. Las dificultades que tienen que enfrentar a diario las personas con discapacidad para acceder a servicios públicos básicos o de regular necesidad son bien conocidas. Además, la discriminación, la exclusión y vulnerabilidad a que están sometidas afecta también a sus familias. Reconocer sus derechos y condiciones implica, como ya se dijo, verlas desde su discapacidad y desde sus múltiples potencialidades, haciendo que estas últimas se aprovechen para el desarrollo social y económico personal, de sus comunidades y de la sociedad. ${ }^{81}$ Realidad que marca la necesidad de hacer un estudio introspectivo de tales urgencias.

Sobre el control difuso de convencionalidad social, la Corte Interamericana de Derechos Humanos en el caso Furlan y Familiares vs. Argentina ${ }^{82}$ "recuerda que el artículo 2 de la Convención obliga a los Estados Parte a adoptar, con arreglo a sus procedimientos constitucionales y a las disposiciones de la Convención, las medi-

81 Programa de lucha contra la pobreza en Lima Metropolitana. (Julio, 2008). La Inclusión de las personas con discapacidad. Sistematización de la intervención de PROPOLI en discapacidad: lecciones aprendidas y recomendaciones para futuras intervenciones. Lima: Unión Europea y Ministerio de la Mujer y Desarrollo Social de Perú (MINDES), p. 10.

82 Corte Interamericana de Derechos Humanos. Caso Furlan y Familiares vs. Argentina, supra nota 6, párr. 300. 
das legislativas o de otro carácter que fueran necesarias para hacer efectivos los derechos y libertades protegidos por la Convención" [itálicas propias]. Las medidas "de otro carácter" deben entenderse desde un criterio preventivo y correctivo, en el caso de obras y obstáculos físicos que impidan atender las necesidades sociales de las personas con discapacidad, en especial para acceder a servicios públicos.

Las medidas de prevención invitan a realizar estudios y análisis sobre las necesidades actuales y futuras de las personas con discapacidad, que puedan ser materializadas en una norma de derecho interno que regule de modo imperativo su garantía acorde con las disposiciones convencionales. No hacerlo significaría incumplir compromisos internacionales, desconocer los derechos que el Estado debe asegurar a estas personas y hacer de las disposiciones letra muerta.

Recordemos que la falta de servicios accesibles a las personas con discapacidad muestra no solo la falta de respuestas sociales e institucionales, sino situaciones cotidianas de indiferencia, discriminación y exclusión, ${ }^{83}$ que de realizarse un adecuado control difuso de convencionalidad social no se presentarían.

En este contexto cabe poner en práctica la rehabilitación basada en la comunidad, introducida en el año 1970 por la oms, como una estrategia que vela por la atención primaria de la salud para la rehabilitación e integración social de las

83 Programa de lucha contra la pobreza en Lima Metropolitana, supra nota 79, p. 12 personas con discapacidad. Uno de sus principales objetivos es "asegurar que las personas con discapacidad puedan desarrollar al máximo sus capacidades físicas y mentales, tener acceso a los servicios y a las oportunidades y ser colaboradores activos dentro de la comunidad y de la sociedad en general (...) eliminando barreras para su participación". ${ }^{84}$ Medidas que pueden conjugarse con las de las instituciones nacionales de protección de los derechos humanos de las personas con discapacidad, velando todas, en cumplimiento de los deberes convencionales, por anclar sus prácticas a los Principios de París, ${ }^{85}$ adoptados por la onu para vigilar el cumplimiento de las obligaciones estatales, formular observaciones al gobierno y armonizar la legislación y las prácticas nacionales. Esta estrategia de corte social exige al Estado cumplir, como primer paso, con el control difuso de convencionalidad social.

Por ello, la Corte Interamericana de Derechos Humanos, en el caso Masacre de Pueblo Bello vs. Colombia, expresa: "la obligación de garantizar los derechos humanos consagrados en la Convención [y otros instrumentos específicos que regulan el derecho de las personas con discapacidad], no se agota con la existencia de un orden normativo dirigido a hacer posible el cumplimiento de esta obligación, sino que comporta

84 Organización Internacional de Trabajo, Organización Mundial de la Salud, Organización de las Naciones Unidas para la Educación, la Ciencia y la Cultura. (2004). Estrategia para la rehabilitación, la igualdad de oportunidades, la reducción de la pobreza y la integración social de las personas con discapacidad. Documento de posición conjunta, Suiza: оІт, oms, Unesco, p. 3.

Asamblea General de la onu. (20 de diciembre de 1993). Principios de París. Resolución n. ${ }^{\circ} 48 / 124$. 
la necesidad de una conducta gubernamental que asegure su existencia, en la realidad, de una eficaz garantía del libre y pleno ejercicio de los derechos humanos", ${ }^{86}$ subsumido en el control difuso de convencionalidad social.

Control social que resulta indesligable del control difuso de convencionalidad jurídico, entendido como la obligación general de cada Estado parte de adecuar su derecho interno a las disposiciones convencionales para garantizar los derechos en ellas consagradas y su efectividad (effet utile), tal como lo requiere el artículo 2 de la $\mathrm{CADH}^{87}$ Campo en el que la Corte Interamericana de Derechos Humanos puede ejercer el escrutinio normativo, esto es, el pronunciamiento realizado por un órgano jurisdiccional internacional, que contiene un análisis crítico y razonado de la compatibilidad de una norma de derecho interno respecto de los preceptos establecidos en un tratado de derechos humanos. Este es diferente al control normativo, que es facultad de los Estados, opera respecto de disposiciones que han sido materia de escrutinio normativo ${ }^{88}$ y vela por la supervisión directa del control de convencionalidad, debido a que la fuente interna e internacional se retroalimentan. ${ }^{89}$

86 Corte Interamericana de Derechos Humanos. Caso Masacre de Pueblo Bello vs. Colombia. Sentencia de 31 de enero de 2006. (Fondo, Reparaciones y Costas). Serie C n. ${ }^{\circ} 140$, párr. 142.

87 Comisión Interamericana de Derechos Humanos. Caso 12.525. Nelson Iván Serrano Sáenz vs. Ecuador. Informe n. ${ }^{\circ} 84 / 09,06$ de agosto de 2009, párr. 76 .

88 Silvera, A. (2003). Ejecución de las sentencias de la Corte Interamericana de Derechos Humanos: el caso del escrutinio normativo. Agenda Internacional, IX(18), p. 67.

89 Torres Zúñiga, N. (Julio, 2009). Las relaciones entre la Corte Interamericana de Derechos Humanos y los tribunales locales. Ob. cit., p. 42.
Acoplar ello al acceso de las personas con discapacidad a servicios públicos conlleva el deber de adoptar las medidas legales necesarias para su cumplimiento y aplicación material en los diferentes niveles de gobierno. De existir una norma contraria a la CADH O a instrumentos internacionales en materia de discapacidad, o de omitir las obligaciones internacionales contraídas, es el poder judicial, propiamente las Cortes de justicia nacional las que deberán actuar conforme a derecho, inclusive cuando el poder legislativo (Parlamento o Congreso) falla en su tarea de suprimir o adoptar leyes contrarias a la Convención Americana. ${ }^{90}$ Claudio Grossman, excomisionado de la Comisión Interamericana de Derechos Humanos, en esta línea señala: "Paulatinamente, se ha ido masificando el uso de jurisprudencia transnacional que cada vez toma más fuerza en el ámbito interno [sic] los poderes judiciales" 91 , sin embargo, no se emplean las disposiciones legales de manera adecuada, aspecto que se conseguiría de aplicar de modo conjunto el control difuso de convencionalidad tanto social como jurídico, por no ser viable usar normas de derecho interno como justificación para incumplir obligaciones asumidas en el derecho internacional, acorde con el artículo $26^{\circ}$ de la Convención de Viena sobre el Derecho de los Tratados de 1969.

90 Lucchetti, A. (2008). Los jueces y algunos caminos del control de convencionalidad. En Control de Convencionalidad. Buenos Aires, Argentina: Editorial Ediar, p. 143.

91 Grossman, C. (2005). El futuro del Sistema Interamericano de Derechos Humanos. Saberes, revista de estudios jurídicos, económicos y sociales, 2, p. 12. 
Por consiguiente, los órganos del poder judicial tendrán que ejercer no solo un control de constitucionalidad, sino también de convencionalidad ex officio entre las normas internas y la Convención Americana, ${ }^{92}$ de modo que su compatibilidad se vea reflejada al desarrollar jurídicamente los parámetros sobre el derecho de las personas con discapacidad al acceso a los servicios públicos, que como se recuerda, son: a) Eliminar barreras físicas, arquitectónicas, de comunicación, información y transporte existentes; b) Vivir de forma independiente; c) Participación activa en sociedad; d) Derecho a la vida privada; y e) Igualdad de oportunidades. Estos se encuentran entrelazados, y de no tener una regulación normativa interna reducirían el control difuso de convencionalidad jurídico que deben ejercer de oficio dentro sus respectivos sistemas normativos.

No basta, per se, que existan normas referentes a los parámetros mencionados; se requiere dictar medidas complementarias, como reglamentos y guías, que regulen su aplicación erga omnes sin discriminación, y aplicar el control difuso de convencionalidad social que incidiría en la aplicación inmediata de la norma adoptada.

Las sentencias de la Corte Interamericana de Derechos Humanos, en el aspecto citado, ejercen un poder determinante en el control difuso de convencionalidad jurídico, aunque no siempre tienden a la derogación de una norma inter-

92 Corte Interamericana de Derechos Humanos. Caso Almonacid Arellano y otros vs. Chile. Sentencia de 26 de septiembre de 2006. (Excepciones Preliminares, Fondo, Reparaciones y Costas). Serie C n. ${ }^{\circ} 154$, párr. 124. na (ley en sentido formal o material), sino a la necesidad de incorporar disposiciones de derecho nacional que hagan efectivos determinados derechos convencionales. ${ }^{93}$

En cuanto al control difuso de convencionalidad social es pertinente precisar que este apunta a cuestiones que, si bien de manera expresa no se estipulan, requieren protección en atención a la situación especial de vulnerabilidad de las personas con discapacidad y al respeto a su dignidad humana, conforme lo establecen la CADH y los tratados internacionales. Esta protección especial se ampliará no solo con el estudio y análisis de la experiencia empírica sino con los criterios jurisprudenciales desarrollados por los tribunales Internacionales, y que marcan el derrotero frente a nuevas situaciones que requieran de regulación. De obviarse este aspecto será imposible adicionar al ordenamiento jurídico interno medidas eficaces que aseguren, como bien lo mencionamos, la igualdad de las personas con discapacidad en el acceso a servicios públicos.

Sin embargo, la no ratificación de la Convención Americana para la Eliminación de todas las Formas de Discriminación contra las Personas con Discapacidad y de otros instrumentos especiales no resta responsabilidad a los Estados respecto a lo dispuesto por la $\mathrm{CADH}$, la Declaración Americana de los derechos del hombre y del ciudadano, y la Declaración Universal de los Derechos Humanos, considerando el alto grado

\footnotetext{
93 Castillo Alva, J. L., (Septiembre, 2012). La validez de una sentencia penal. Ob. cit., p. 66. Supra nota 76 .
} 
de vulnerabilidad que la discapacidad trae consigo y la especial protección estatal que esta demanda.

\section{CONCLUSIONES}

Tutelar los derechos de las personas con discapacidad conlleva, en primer lugar, comprender las deficiencias físicas, mentales, intelectuales y sensoriales de naturaleza permanente o temporal que padezcan; Ias limitaciones en la actividad y las restricciones para participar de la vida económica y social, principalmente. En segundo lugar, adoptar medidas regulatorias tendientes a eliminar barreras físicas, arquitectónicas, de comunicación, información y transporte; cautelar el derecho a la autonomía; asegurar la participación activa en sociedad; el derecho a la vida e igualdad de condiciones. En tercer lugar, ofrecer formación a las personas involucradas directamente con las personas con discapacidad, y a estas últimas proporcionarles formas de asistencia.

Lo anterior, considerado como un todo indivisible si es que, en realidad, se quiere evitar todo tipo de vulneración a sus derechos (vida, vida privada, libertad, igualdad ante la ley, personalidad jurídica, entre otros) por acción o por omisión, o actos discriminatorios no tolerables de manera general y menos en personas con discapacidad que reclaman una protección especial, es decir, garantías adicionales.

Siendo plausible establecer una distinción a las personas con discapacidad, siempre que esta sea progresiva o positiva, es decir objetiva y razonable para garantizar sus derechos.

Derechos que de vulnerar por acción u omisión el acceso a servicios públicos, atentaría inexorablemente contra el derecho a la vida, que es base de las normas convencionales, si se tiene en cuenta que tanto jurídica como política, administrativa y culturalmente es intolerable que, además de la discapacidad, deban soportar limitaciones impuestas por el Estado, por el sector privado o por la sociedad.

Para el cumplimiento de los instrumentos internacionales en materia de protección del derecho al acceso a servicios públicos de las personas con discapacidad resulta necesario orientar los esfuerzos estatales a un doble control difuso de convencionalidad: en lo social para develar las barreras sociales existentes, y en lo jurídico para incluir disposiciones que atiendan las necesidades sociales determinadas empíricamente o mediante estudios, con miras a asegurarles garantías adicionales a las del simple acceso a los servicios públicos.

\section{Bibliografía}

Cabanellas, G. (1981). Diccionario Enciclopédico de Derecho Usual. (20 ed.). Tomo V. Argentina: Editorial Heliasta.

Castilla, K. (2011). El control de convencionalidad: un nuevo debate en México a partir de la sentencia del Caso Radilla Pacheco. Anuario Mexicano de Derecho Internacional, XI. 
Castillo Alva, J. (septiembre, 2012). La validez de una sentencia penal. Acerca de la calificación de un hecho como grave violación a los derechos humanos: entre el respeto a las normas internas y el cumplimiento de la jurisprudencia de la Corte IDH, a propósito de la sentencia del caso Barrios Altos (Primera parte). Gaceta Constitucional, 39.

Comisión Interamericana de Derechos Humanos, Caso 12.308, Manoel Leal de Olivera vs. Brasil. Informe n. ${ }^{\circ} 37 / 10,17$ de marzo de 2010.

Comisión Interamericana de Derechos Humanos, Caso 12.009, Leydi Dayán Sánchez vs. Colombia. Informe n. ${ }^{\circ}$ 43/09. (Fondo). 23 de julio de 2008.

Comisión Interamericana de Derechos $\mathrm{Hu}$ manos. Caso 12.525. Nelson Iván Serrano Sáenz vs. Ecuador. Informe n. ${ }^{\circ}$ 84/09, 06 de agosto de 2009.

Consejo de Europa, Comité de Ministros. (07 de mayo de 1992). Recomendación n. ${ }^{\circ} 1185$ (1992) sobre las políticas de rehabilitación para discapacitados, aprobada por la Asamblea Parlamentaria del Consejo de Europa.

Consejo de Europa, Comité de Ministros. (9 de abril de 1992). Recomendación $R$ (92)6 sobre derechos humanos, aprobada por la Asamblea Parlamentaria del Consejo de Europa.

Consejo de Europa, Comité de Ministros. (05 de abril de 2006). Convenio Europeo para la
Protección de los Derechos Humanos y de las Libertades Fundamentales. Línea de Acción n. ${ }^{\circ} 12$.

Consejo de Europa, Comité de Ministros. (5 de abril de 2006). Recomendación Rec (2006) 5 sobre el Plan de Acción del Consejo de Europa para la Promoción de Derechos y la Plena Participación de las Personas con Discapacidad en la Sociedad: mejor calidad de vida de las personas con discapacidad en Europa 2006-2015, aprobada durante la $961^{\circ}$ reunión de Delegados de Ministros.

Conferencia Internacional Americana. (1948). Declaración Americana de los Deberes y Derechos del Hombre, aprobada en la Novena Conferencia realizada en Bogotá, Colombia.

Organización de los Estados Americanos. (6 de julio de 1999). Convención Interamericana para la Eliminación de Todas las Formas de Discriminación contra las Personas con Discapacidad, aprobada en el vigésimo noveno periodo de sesiones de la Asamblea General de la Organización de los Estados Americanos. Ciudad de Guatemala.

Correa-Montoya, L. (2009). Panorama de la protección jurisprudencial de los derechos humanos de las personas con discapacidad en Colombia. Vniversitas, 118, 115-139.

Corte Constitucional de Colombia. Sentencia T-288/1995 de 5 de julio de 1995. M. P.: Eduardo Cifuentes Muñoz. 
Corte Constitucional de Colombia. Sentencia T-595-2003 de 17 de julio de 2003. M. P.: Inés Vargas Fernández.

Corte Interamericana de Derechos Humanos. Caso "La Última Tentación de Cristo" (Olmedo Bustos y otros) vs. Chile. Sentencia de 5 de febrero de 2001. Serie C n. ${ }^{\circ} 73$.

Corte Interamericana de Derechos Humanos. Caso Comunidad Indígena Xákmok Kásek vs. Paraguay. Sentencia del 24 de agosto de 2010. (Fondo, Reparaciones y Costas). Serie C n. ${ }^{\circ} 214$.

Corte Interamericana de Derechos Humanos. Caso de los "Niños de la Calle" (Villagrán Morales y otros) vs. Guatemala. Sentencia de 19 de noviembre de 1999. Serie C n. ${ }^{\circ} 63$.

Corte Interamericana de Derechos Humanos. Caso Tristán Donoso vs. Panamá. Sentencia del 27 de enero de 2009. (Excepciones Preliminares, Fondo, Reparaciones y Costas). Serie $\mathrm{C}$ n. ${ }^{\circ} 193$.

Corte Interamericana de Derechos Humanos. Caso Ximenes Lopes vs. Brasil, Sentencia de 04 de julio de 2006. Serie C n. ${ }^{\circ} 149$.

Corte Interamericana de Derechos Humanos. Caso Almonacid Arellano y otros vs. Chile. Sentencia de 26 de septiembre de 2006. (Excepciones Preliminares, Fondo, Reparaciones y Costas). Serie C n. 154.

Corte Interamericana de Derechos Humanos. Caso Apitz Barbera y otros ("Corte Primera de lo Contencioso Administrativo") vs. Venezuela. Sentencia de 05 de agosto de 2008. (Excepción Preliminar, Fondo, Reparaciones y Costas). Serie C n. 182.

Corte Interamericana de Derechos Humanos. Caso Artavia Murillo y otros "fecundación in vitro" vs. Costa Rica. Sentencia de 28 de noviembre de 2012. (Excepciones, Fondo, Reparaciones y Costas). Serie C n. 257.

Corte Interamericana de Derechos Humanos. Caso Baldeón García vs. Perú. Sentencia de 06 de abril de 2006. (Fondo, Reparaciones y Costas). Serie C n. 147.

Corte Interamericana de Derechos Humanos. Caso Bámaca Velásquez vs. Guatemala. Sentencia de 25 de noviembre de 2000. (Fondo, Reparaciones y Costas). Serie C n. ${ }^{\circ} 70$.

Corte Interamericana de Derechos Humanos. Caso Chocrón Chocrón vs. Venezuela. Sentencia de 01 de julio de 2011. (Excepción Preliminar, Fondo, Reparaciones y Costas). Serie C n. ${ }^{\circ} 227$.

Corte Interamericana de Derechos Humanos. Caso Comunidad Indígena Sawhoyamaxa vs. Paraguay. Sentencia de 29 de marzo de 2006. (Fondo, Reparaciones y Costas). Serie C n. ${ }^{\circ} 146$.

Corte Interamericana de Derechos Humanos. Caso de la Masacre de Mapiripán vs. Colombia. Sentencia de 15 de septiembre de 2005. 
(Fondo, Reparaciones y Costas). Serie C n. ${ }^{\circ}$ 134.

Corte Interamericana de Derechos Humanos. Caso de la Masacre de Pueblo Bello vs. CoIombia. Sentencia 31 de enero de 2006. Serie $\mathrm{C} n .^{\circ} 140$.

Corte Interamericana de Derechos Humanos. Caso de las Niñas Yean y Bosico vs. República Dominicana. Sentencia de 8 de septiembre de 2005. (Fondo, Reparaciones y Costas). Serie C n. ${ }^{\circ} 130$.

Corte Interamericana de Derechos Humanos. Caso de los Hermanos Gómez Paquiyauri vs. Perú. Sentencia de 08 de julio de 2004. (Fondo, Reparaciones y Costas). Serie C n. ${ }^{\circ} 110$.

Corte Interamericana de Derechos Humanos. Caso Escher y otros vs. Brasil. Sentencia de 06 de julio de 2009. Serie C n. 200.

Corte Interamericana de Derechos Humanos. Caso Furlan y Familiares vs. Argentina. Sentencia del 31 de agosto de 2012. (Excepciones Preliminares, Fondo, Reparaciones y Costas). Serie C n. ${ }^{\circ} 246$.

Corte Interamericana de Derechos Humanos. Caso González y otras ("Campo Algodonero") vs. México. Sentencia de 16 de noviembre de 2009. (Excepción Preliminar, Fondo, Reparaciones y Costas). Serie C n. 205.

Corte Interamericana de Derechos Humanos. Caso Ibsen Cárdenas e Ibsen Peña vs. Bolivia. Sentencia de 01 de septiembre de 2010.
(Fondo, Reparaciones y Costas). Serie C n. ${ }^{\circ}$ 127.

Corte Interamericana de Derechos Humanos. Caso J. vs Perú. Sentencia de 27 de noviembre de 2013. (Excepción Preliminar, Fondo, Reparaciones y Costas). Serie C n. ${ }^{\circ} 275$.

Corte Interamericana de Derechos Humanos. Caso Juan Humberto Sánchez vs. Honduras. Sentencia de 07 de junio de 2003. (Excepción Preliminar, Fondo, Reparaciones y Costas). Serie C n. ${ }^{\circ} 99$.

Corte Interamericana de Derechos Humanos. Caso La Cantuta vs. Perú. Sentencia de 29 de noviembre de 2006. (Fondo, Reparaciones y Costas). Serie C n. ${ }^{\circ} 173$.

Corte Interamericana de Derechos Humanos. Caso Luna López vs. Honduras. Sentencia de 10 de octubre de 2013. (Fondo, Reparaciones y Costas). Serie C n. 269.

Corte Interamericana de Derechos Humanos. Caso Masacre de Ituango vs. Colombia. Sentencia 01 de julio de 2006. Serie C n. ${ }^{\circ} 148$.

Corte Interamericana de Derechos Humanos. Caso Masacre de Santo Domingo vs. Colombia. Sentencia de 30 de noviembre de 2012. (Excepciones Preliminares, Fondo y Reparaciones). Serie C n. ${ }^{\circ} 259$.

Corte Interamericana de Derechos Humanos. Caso Myrna Mack Chang vs. Guatemala. Sentencia de 25 de noviembre de 2003. (Fondo, Reparaciones y Costas). Serie C n. ${ }^{\circ} 101$. 
Corte Interamericana de Derechos Humanos. Caso Suárez Peralta vs. Ecuador. Sentencia de 21 de mayo de 2013. (Excepciones Preliminares, Fondo, Reparaciones y Costas). Serie $\mathrm{C}$ n. ${ }^{\circ} 261$.

Corte Interamericana de Derechos Humanos. Caso Ticona Estrada y otros vs. Bolivia. Sentencia de 27 de noviembre de 2008. (Fondo, Reparaciones y Costas). Serie C n. ${ }^{\circ} 191$.

Corte Interamericana de Derechos Humanos. Caso Torres Millacura y otros vs. Argentina. Sentencia de 26 de agosto de 2011. (Fondo, Reparaciones y Costas).

Corte Interamericana de Derechos Humanos. Caso Velásquez Rodríguez vs. Honduras. Sentencia de 29 de julio de 1988. (Fondo). Serie $\mathrm{C}$ n. ${ }^{\circ} 4$.

Corte Interamericana de Derechos Humanos. Condición jurídica y derechos de los migrantes indocumentados. Opinión Consultiva OC18/03 de 17 de septiembre de 2003. Serie A n. ${ }^{\circ} 18$.

Corte Interamericana de Derechos Humanos. Propuesta de modificación a la Constitución Política de Costa Rica, relacionada con la naturalización. Opinión Consultiva OC-4-84, de 19 de enero de 1984 . Serie A n. ${ }^{\circ} 4$.

Egea García. C. y Saravia Sánchez, A. (Noviembre de 2001). Clasificaciones de la Organización Mundial de la Salud sobre discapacidad. Artículos y notas, p. 10.
European Court of Human Rights. Case "relating to certain aspects of the laws on the use of languages in education in Belgium" v. Belgium. Application No.1474/62, Judgment Strasbourg of 23 July 1968.

European Court of Human Rights. Case D.H. and others v. Czech Republic. Application $N^{\circ} 57325 / 00$, Judgment Strasbourg of 13 November 2005.

European Court of Human Rights. Case Hugh Jordan v. United Kingdom. Application No. 24746/94, Judgment Strasbourg of 04 May 2001.

European Court of Human Rights. Case of Đorđević v. Croatia. Application No. 41526/10. Judgment Strasbourg of 24 July 2012.

European Court of Human Rights. Case of Wessels-Bergervoet v. The Netherlands. Application No. 34462/97, Judgment Strasbourg of 4 June 2002.

European Court of Human Rights. Case Petrovic v. Austria. Application No. 20458/92, Judgment Strasbourg of 27 of March 1998, Reports 1998-II.

European Court of Human Rights. Case WiIlis v. The United Kingdom. Application No. 36042/97, Judgment Strasbourg of 11 June 2002. 
Fix Zamudio, H. (2010). Los derechos humanos y su protección internacional. Perú: Editorial Grijley.

García-Sayán, D. (Abril, 2009). Justicia Interamericana y Tribunales Nacionales. En Aspectos del derecho procesal constitucional. Estudios en homenaje a Héctor Fix-Zamudio en sus cincuenta años como investigador del derecho (colaboraciones peruanas). Perú: Editorial Moreno.

Grossman, C. (2005). El futuro del Sistema Interamericano de Derechos Humanos. Saberes, revista de estudios jurídicos, económicos y sociales, 2.

Instituto Interamericano de Derechos Humanos. (Junio, 2008). Derechos de las personas con discapacidad. Módulo 6. San José de Costa Rica: ॥DH.

Lucchetti, A. (2008). Los jueces y algunos caminos del control de convencionalidad. En Control de Convencionalidad. Buenos Aires, Argentina: Editorial Ediar.

Naciones Unidas, Asamblea General. (20 de diciembre de 1993). Principios de Paris. Resolución n. ${ }^{\circ} 48 / 124$.

Naciones Unidas, Asamblea General. (4 de marzo de 1994). Normas uniformes sobre la igualdad de oportunidades para las personas con discapacidad. (AG/RES/48/96).
Naciones Unidas, Comité de Derechos Económicos, Sociales y Culturales. (12 de septiembre de 1994). Observación General n. $^{\circ}$ 5. Personas con discapacidad (E/C.12/1994/13).

Naciones Unidas, Comité de los Derechos de las Personas con Discapacidad del Alto Comisionado para los Derechos Humanos. (17 a 28 de septiembre de 2012). Observaciones finales sobre el informe inicial de la Argentina (CRPD/C/ARG/CO/1). Ginebra: onU.

Naciones Unidas, Comité de los Derechos de las Personas con Discapacidad del Alto Comisionado para los Derechos Humanos. (16 al 20 de abril de 2012). Observaciones finales sobre el informe inicial del Perú (CRPD/C/PER/O/1). Ginebra: onu.

Naciones Unidas, Comité de los Derechos de las Personas con Discapacidad del Alto Comisionado para los Derechos Humanos. (02 al 13 de septiembre de 2013). Observaciones finales sobre el informe inicial de El Salvador (CRPD/C/SLV/CO/1). Ginebra: onu.

Naciones Unidas, Comité de los Derechos del Niño. (27 de febrero de 2007). Observación General n. ${ }^{\circ}$ 9. Los derechos de los niños con discapacidad (CRC/C/GC/9).

Naciones Unidas, Comité de los Derechos Humanos. (11 de octubre de 1989). Observación General n. ${ }^{\circ}$ 18. Comentarios generales adoptados por el Comité de los Derechos Humanos, No Discriminación (U.N.Doc.HRI) 
GEN/1/Rev.7). Aprobados en el trigésimo séptimo periodo de sesiones.

Naciones Unidas, Comité sobre los Derechos de las Personas con Discapacidad. Caso H. M. vs. Suecia. Comunicación n. ${ }^{\circ} 3 / 2011$. Dictamen aprobado en su séptimo periodo de sesiones (CRPD/C/7/D/3/2011), 16 al 27 de abril de 2012.

Naciones Unidas, Comité sobre los Derechos de las Personas con Discapacidad. Caso Szilvia Nyusti y Péter Takács vs. Hungría. Comunicación n. ${ }^{\circ}$ 1/2010. Dictamen aprobado en su noveno periodo de sesiones (CRPD/ C/9/D/1/2010), 15 a 19 de abril de 2013.

Naciones Unidas, Comité sobre los Derechos de las Personas con Discapacidad. Caso Zsolt Bujdosó y otros vs. Hungría. Comunicación n. ${ }^{\circ}$ 4/2011. Dictamen aprobado en su décimo periodo de sesiones, (CRPD/C/10/D/4/2011), 20 de septiembre de 2013.

Naciones Unidas, Organización Mundial de la Salud y Banco Mundial. (9 de junio, 2011). Comunicado de Prensa oms/13. New York: oms.

Naciones Unidas, Organización Mundial de la Salud y Banco Mundial. (9 de junio de 2011). Informe mensual sobre la discapacidad (WHO/NMH/VIP/11.03). New York: oms, BID, p. 16.

Naciones Unidas, Organización Mundial de la Salud. (Septiembre, 2013). 10 datos sobre la discapacidad. Recuperado de: www.who.int/ features/factfiles/disability/es/.
Naciones Unidas. (13 de diciembre de 2006). Convención Internacional sobre los Derechos de las Personas con Discapacidad.

Organización de los Estados Americanos, Grupo de Trabajo de la Comisión de Asuntos Jurídicos y Políticos. (05 de diciembre de 2006). Leyes sobre derechos de las personas con discapacidad: vida política y pública. Comentarios al Proyecto de Programa de Acción para el Decenio de las Américas por los Derechos y la Dignidad de las Personas con Discapacidad (2006-2016). Documento presentado por la delegación de los Estados Unidos (OEA/Ser.G/CAJP/GT/DDD-20/06).

Organización de los Estados Americanos, Grupo de Trabajo de la Comisión de Asuntos Jurídicos y Políticos. (05 de junio de 2007). Programa de Acción para el Decenio de las Américas por los Derechos y la Dignidad de las Personas con Discapacidad 2006-2016. (AG/RES.2339 - XXXVII-O/07). Santo DomingO: OEA.

Organización de los Estados Americanos, Grupo de Trabajo de la Comisión de Asuntos Jurídicos y Políticos. (05 de diciembre de 2006). Aportes al Proyecto de Programa de Acción para el Decenio de las Américas por los Derechos y la Dignidad de las Personas con Discapacidad 2006-2016. (OEA/Ser.G/CAJP/GT/ DDD-18/06 corr.1).

Organización de los Estados Americanos, Grupo de Trabajo de la Comisión de Asuntos Jurídicos y Políticos. (06 de diciembre de 2006). 
Comentarios al Proyecto del Programa de Acción para el Decenio de las Américas por los Derechos y la Dignidad de las Personas con Discapacidad (2006-2016), presentados por la Agencia Internacional para los Derechos de las Personas con Discapacidad Mental (OEA/ Ser.G/CAJP/GT/DDD-22/06).

Organización de los Estados Americanos, Grupo de Trabajo de la Comisión de Asuntos Jurídicos y Políticos (6 de diciembre de 2006). Aportes al Proyecto de Programa de Acción para el decenio de las Américas por los derechos y la dignidad de las personas con discapacidad (2006-2016), presentados por la Organización Panamericana de la Salud (OEA/ Ser.G/CAJP/GT/DDD-21/06).

Organización Internacional de Trabajo, Organización Mundial de la Salud, Organización de las Naciones Unidas para la Educación, la Ciencia y la Cultura. (2004). Estrategia para la rehabilitación, la igualdad de oportunidades, la reducción de la pobreza y la integración social de las personas con discapacidad. Documento de posición conjunta. Suiza: oІт, oms, Unesco.

Organización Mundial de la Salud. (Septiembre de 2013). Nota descriptiva $n .^{\circ}$ 352. Recuperado de: http://www.who.int/mediacentre/ factsheets/fs352/es/

Sagüés, N. (2010). Obligaciones internacionales y control de convencionalidad. Estudios Constitucionales, 8(1), 118.
Silvera, A. (2003). Ejecución de las sentencias de la Corte Interamericana de Derechos Humanos: el caso del escrutinio normativo. Agenda Internacional, IX (18).

Torres Zúñiga, N. (Julio, 2009). Las relaciones entre la Corte Interamericana de Derechos Humanos y los tribunales locales. La incorporación de la jurisprudencia internacional en el marco de la resolución de conflictos por jueces nacionales. Gaceta Constitucional, 19.

Tribunal Constitucional del Perú. Acción de amparo interpuesta por Irene Calderón García contra la Empresa Municipal Administradora de Peaje de Lima (EMAPE). Expediente $n$. $^{\circ}$ 00035-2010-PA-TC.

Trömel, S. (2008). La Convención sobre los derechos de las personas con discapacidad y los retos para su implementación. (Ponencia). Foro Convención sobre los Derechos de las Personas con Discapacidad, realizado por la Universidad de los Andes. Bogotá.

Unión Europea y Ministerio de la Mujer y Desarrollo Social de Perú. (Julio, 2008). Programa de lucha contra la pobreza en Lima Metropolitana (PROPOLI). La inclusión de las personas con discapacidad. Sistematización de la intervención de PROPOLI en discapacidad: lecciones aprendidas y recomendaciones para futuras intervenciones. Lima: Autores.

Vidal Ramírez, F. (Julio 2009). El agotamiento de la jurisdicción interna y el acceso a la jurisdicción supranacional. Gaceta Constitucional, 19. 